\title{
Lipolysis: cellular mechanisms for lipid mobilization from fat stores
}

\author{
Gernot F. Grabner ${ }^{1,3}$, Hao Xie ${ }^{1,3}$, Martina Schweiger ${ }^{1,2} \bowtie$ and Rudolf Zechnerer, ${ }^{1,2}$
}

The perception that intracellular lipolysis is a straightforward process that releases fatty acids from fat stores in adipose tissue to generate energy has experienced major revisions over the last two decades. The discovery of new lipolytic enzymes and coregulators, the demonstration that lipophagy and lysosomal lipolysis contribute to the degradation of cellular lipid stores and the characterization of numerous factors and signalling pathways that regulate lipid hydrolysis on transcriptional and post-transcriptional levels have revolutionized our understanding of lipolysis. In this review, we focus on the mechanisms that facilitate intracellular fatty-acid mobilization, drawing on canonical and noncanonical enzymatic pathways. We summarize how intracellular lipolysis affects lipid-mediated signalling, metabolic regulation and energy homeostasis in multiple organs. Finally, we examine how these processes affect pathogenesis and how lipolysis may be targeted to potentially prevent or treat various diseases.

atty acids (FAs) are essential biomolecules for all organisms. Their oxidation generates the highest energy yield for ATP or heat production of all common energy substrates. They are indispensable components of membrane lipids, and FA anchors enable peripheral membrane proteins to be tethered to biological membranes. Additionally, specific FAs act as highly bioactive signalling molecules or serve as their precursors. Besides these vital functions, FAs also exert toxic properties ('lipotoxicity') when their intra- and/or extracellular concentrations exceed physiological levels. Lipotoxicity results from the ability of FAs to act as detergents, to affect acid-base homeostasis and to generate highly bioactive lipids, such as ceramides and diradylglycerols (diglycerides, DGs). Together, these processes cause cellular stress and dysfunction, leading to various forms of cell death ${ }^{1}$.

To efficiently and safely store large amounts of FAs in cells and tissues, they are covalently esterified to the trivalent alcohol glycerol to yield triradylglycerols, commonly called triglycerides (TGs) or 'fat'. Essentially every cell type can store TGs to some degree in intracellular organelles termed lipid droplets (LDs) ${ }^{2}$. In mammals and many other vertebrates, the majority of TGs is deposited in adipocytes of adipose tissue. While TGs represent an efficient, inert form of FAs for storage and transport, they are unable to traverse cell membranes. Accordingly, TG transport into or out of cells either requires their hydrolytic breakdown into FAs and glycerol or their specialized-vesicle-mediated transport across cell membranes. The latter process comprises secretion and uptake of TG-rich lipoproteins or TG transport by extracellular vesicles (EVs). The hydrolysis of TGs is catalysed by lipases in a process called lipolysis. Extracellular lipolysis in the gastrointestinal tract and the vascular system degrades TGs to provide FAs and monoradylglycerols (monoglycerides, MGs) to the underlying parenchymal tissues. Conversely, intracellular lipolysis releases FAs from LD-associated TGs in the cytoplasm or lipoprotein-associated TGs in lysosomes. Extracellular lipases of the digestive tract and the vascular system mostly belong to the pancreatic lipase gene family. Intracellular lipases are structurally unrelated to this family and have been subclassified as (1) lipases with an optimum $\mathrm{pH}$ around 7 ('neutral lipases'), which are responsible for the degradation of cytosolic LDs, and (2) lipases with an optimum pH around 5 ('acid lipases'), which are localized to lysosomes. Accordingly, the two intracellular canonical pathways responsible for TG degradation are termed neutral and acid lipolysis (Fig. 1). In accordance with the fundamental function of lipases, their dysfunction or deficiency often causes severe pathologies including dyslipidaemias and lipid-storage diseases. More indirectly, lipase activities and lipolytic processes affect many aspects of homeostasis and have been associated with the pathogenesis of obesity, type 2 diabetes, nonalcoholic fatty liver disease (NAFLD), cancer, heart disease, cachexia, infectious diseases and others.

\section{Canonical enzymology of neutral lipolysis}

Recognition that enzyme-catalysed TG hydrolysis must precede membrane passage was achieved early in the 20th century ${ }^{3}$, yet it took more than 50 years to identify and characterize the first intracellular TG hydrolase that participates in the process. In 1964, Steinberg and colleagues described hormone-sensitive lipase (HSL) as the key hydrolase in the degradation of TGs and DGs and the role of monoglyceride lipase (MGL) in MG hydrolysis in adipocytes ${ }^{4}$. HSL was considered rate-limiting for TG hydrolysis for the following four decades, but observations that HSL-deficient mice maintained hormone-induced FA release in adipose tissue, lacked obesity and accumulated DGs ${ }^{5,6}$ finally argued for the involvement of alternative enzymes and mechanisms in TG hydrolysis. An extensive search for these alternatives led to the discovery of a new enzyme, called adipose triglyceride lipase (ATGL) ${ }^{7}$ or $\mathrm{Ca}^{+}{ }^{+}$-independent phospholipase-A2- $\zeta$ (iPLA2- $\zeta)^{8}$, and its coactivator, named $\alpha / \beta$ hydrolase domain-5 (ABHD-5; also called comparative gene identification-58, CGI-58) ${ }^{9}$. The biochemical characteristics and enzymatic activities of ATGL, HSL and MGL are summarized in Table 1 and Fig. 1.

Adipose triglyceride lipase. Human adipose triglyceride lipase (ATGL) is a 504-amino-acid protein. It harbours a patatin domain named after a structural unit in patatin, which is a relatively weak 


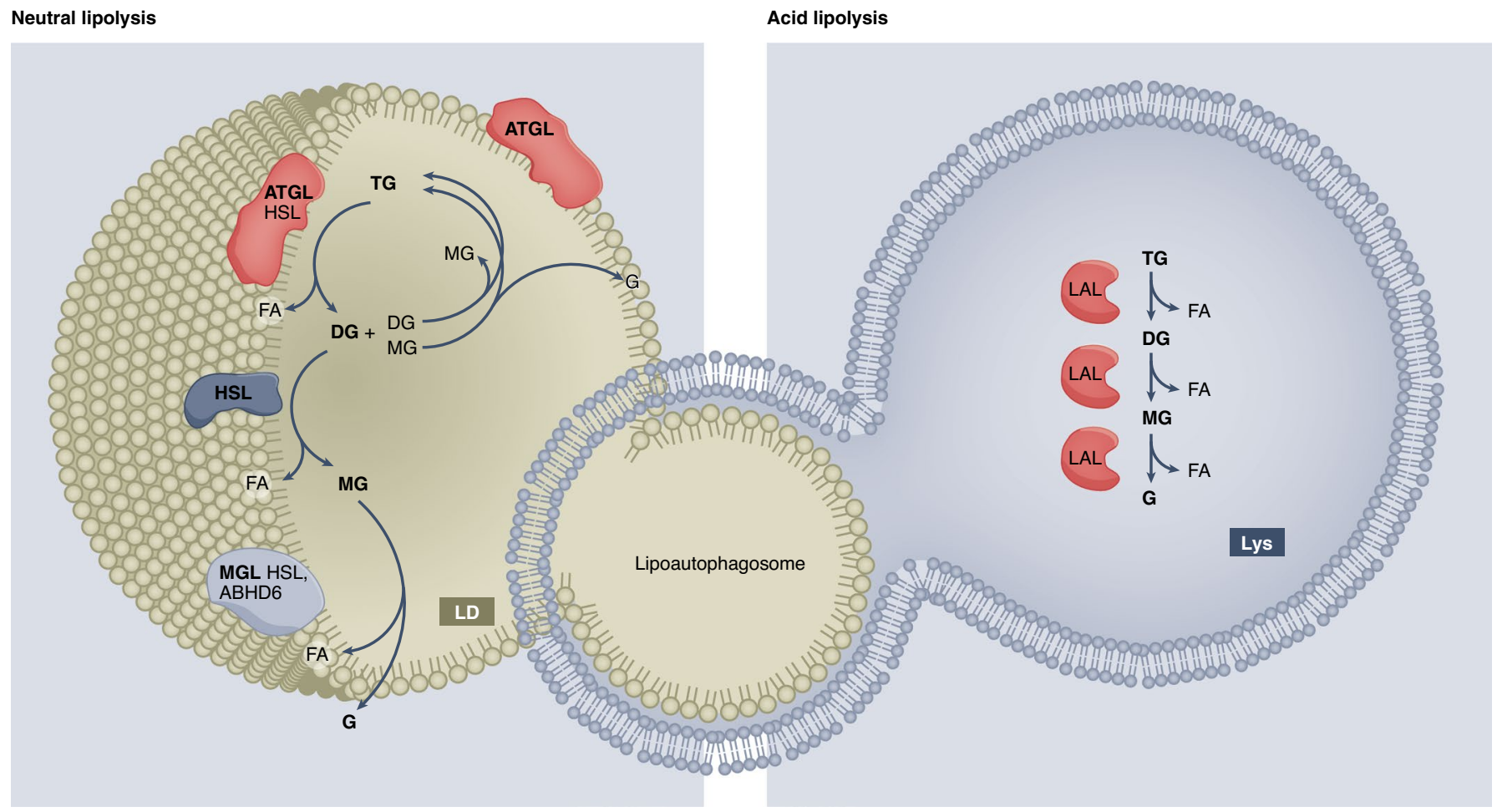

Fig. 1 Canonical pathways of lipolysis. Consecutive hydrolysis of TGs by ATGL, HSL and MGL or ABHD6, generating FAs and glycerol (G).

Transesterification of DGs or MGs with DG, generating TGs, is catalysed by ATGL. In acid lipolysis, TGs are sequestered from LDs via lipophagy and are subsequently hydrolysed by LAL in lysosomes (Lys), generating FAs and glycerol.

phospholipase present in potato tubers ${ }^{7}$. The human genome carries nine genes encoding patatin-domain-containing proteins, which are designated patatin-like phospholipase domain 1-9 (PNPLA1PNPLA9 $)^{10}$. PNPLA2 encodes ATGL. The patatin domain of ATGL is embedded in a typical $\alpha-\beta-\alpha$ hydrolase fold located in the amino-terminal half of the enzyme. It contains a catalytic dyad consisting of S47 and D166. Interestingly, the carboxy-terminal half of the enzyme is dispensable for enzyme activity on lipid emulsions but essential for LD binding and TG hydrolysis in cells ${ }^{11}$. The molecular basis for the requirement of this C-terminal region for enzyme binding to LDs is poorly understood. It may involve a hydrophobic stretch (amino acids 315 to 364) and two potential phosphorylation sites (S406, S430). However, the protein kinases thought to be involved and the impact of ATGL phosphorylation on its LD localization and activity remain controversial ${ }^{12,13}$ and require further study.

Long-chain FA-containing TGs represent by far the best substrates for ATGL, while FA esters in DGs, glycerophospholipids or retinylesters are only poorly hydrolysed. Interestingly, however, the enzyme exhibits transacylase activity leading to the formation of TG and $\mathrm{MG}^{8,14,15}$ from two DG molecules in a disproportionation reaction. Whether this anabolic function of ATGL is physiologically relevant remains unanswered, as is the question of whether ATGL acts as a transacylase with alternative FA-donor or FA-acceptor substrates. ATGL shares transacylation activity with other members of the PNPLA family, including PNPLA1 and PNPLA3 $\left(\right.$ refs. ${ }^{8,16}$ ). Overall, despite a high potential for physiological relevance, this coenzyme-A-independent esterification reaction and its role in lipid remodelling remain elusive.

Specific transport mechanisms guide ATGL from the endoplasmic reticulum (ER) membrane to LDs. The structural features within ATGL that determine its effective trafficking are still insufficiently understood. More is known about the role of factors involved in ATGL transport. Deletion of key transport vesicle components or effectors, including ADP ribosylation factor-1 (ARF-1), small GTP-binding protein-1 (SAR-1) or Golgi-Brefeldin A resistance factor (GBF-1), as well as deficiency of the coat protein complex-I (COP-I), prevent ATGL translocation and lead to defective TG hydrolysis and LD accumulation ${ }^{17,18}$. The list of factors that affect ATGL translocation was recently extended by oxysterol-binding protein like-2 (OSBP-2) and family with sequence similarity 134, member B (FAM134B). OSBP-2 forms a complex with the COP-I subunit COP-B1 and binds ATGL, directing the enzyme to LDs ${ }^{19}$. FAM134B is a Golgi-associated protein that regulates the vesicular transport of ATGL and other proteins to LDs via Arf-related protein-1 (ARFRP1) ${ }^{20}$.

Loss-of-function mutations in the PNPLA2 gene cause neutral lipid storage disease with myopathy (NLSDM) in humans ${ }^{21}$. Currently, approximately 100 people with the condition with more than 30 different mutations have been identified. Onset and severity of disease are highly variable, arguing for gene-gene and gene-environment interactions that contribute to the clinical presentation of the disease ${ }^{22}$. Most people with the disease develop steatosis in multiple tissues, with TG deposition in cardiac and skeletal muscle, pancreas, liver and leucocytes (Jordan's anomaly). Progressive skeletal myopathy is common in people with NLSDM and leads to pronounced motor impairment. More than half of all affected individuals have severe dilated cardiomyopathy, and many require heart transplantation for survival ${ }^{23}$.

ATGL deficiency in mice phenocopies many of the clinical findings in people with NLSDM, but the murine condition is more serious, leading to cardiomyopathy and death without exception when the animals are 3 to 4 months old ${ }^{24}$. ATGL deficiency in the heart leads not only to a severe TG accumulation in cardiomyocytes, but also to a striking defect in the activation of the transcription factor peroxisome-proliferator-activated receptor- $\alpha$ (PPAR $\alpha)$, reduced 

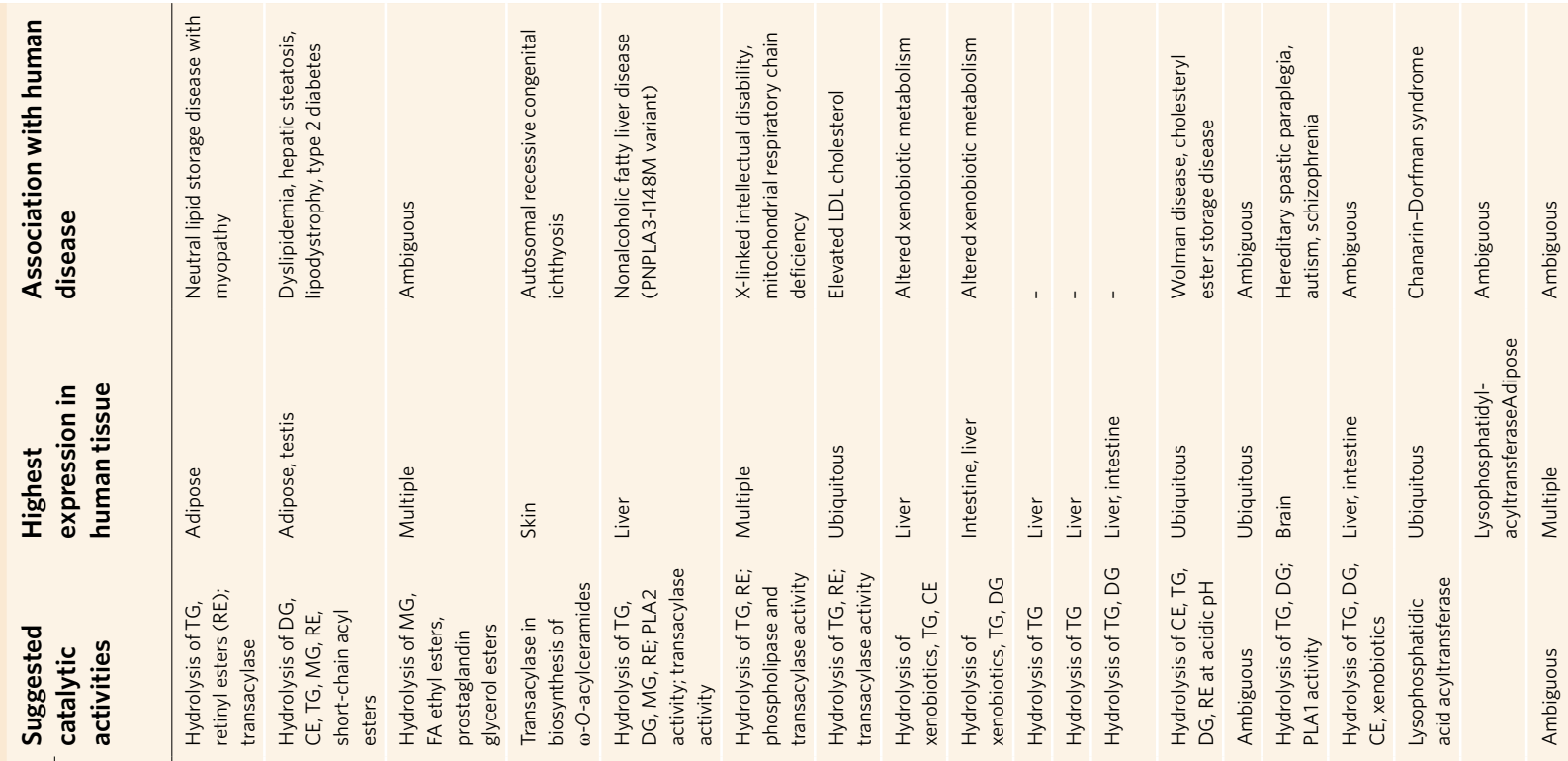

京

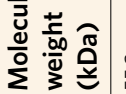
:

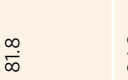
:

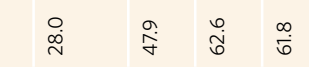

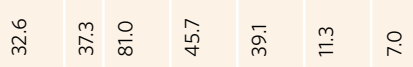

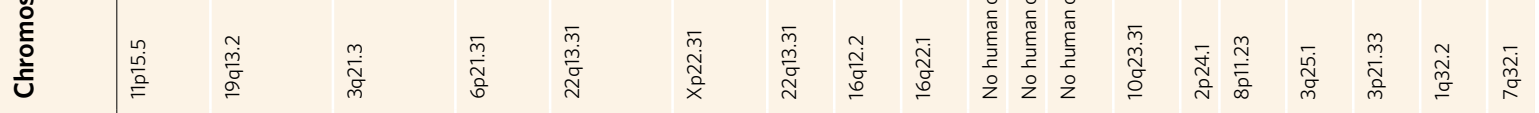

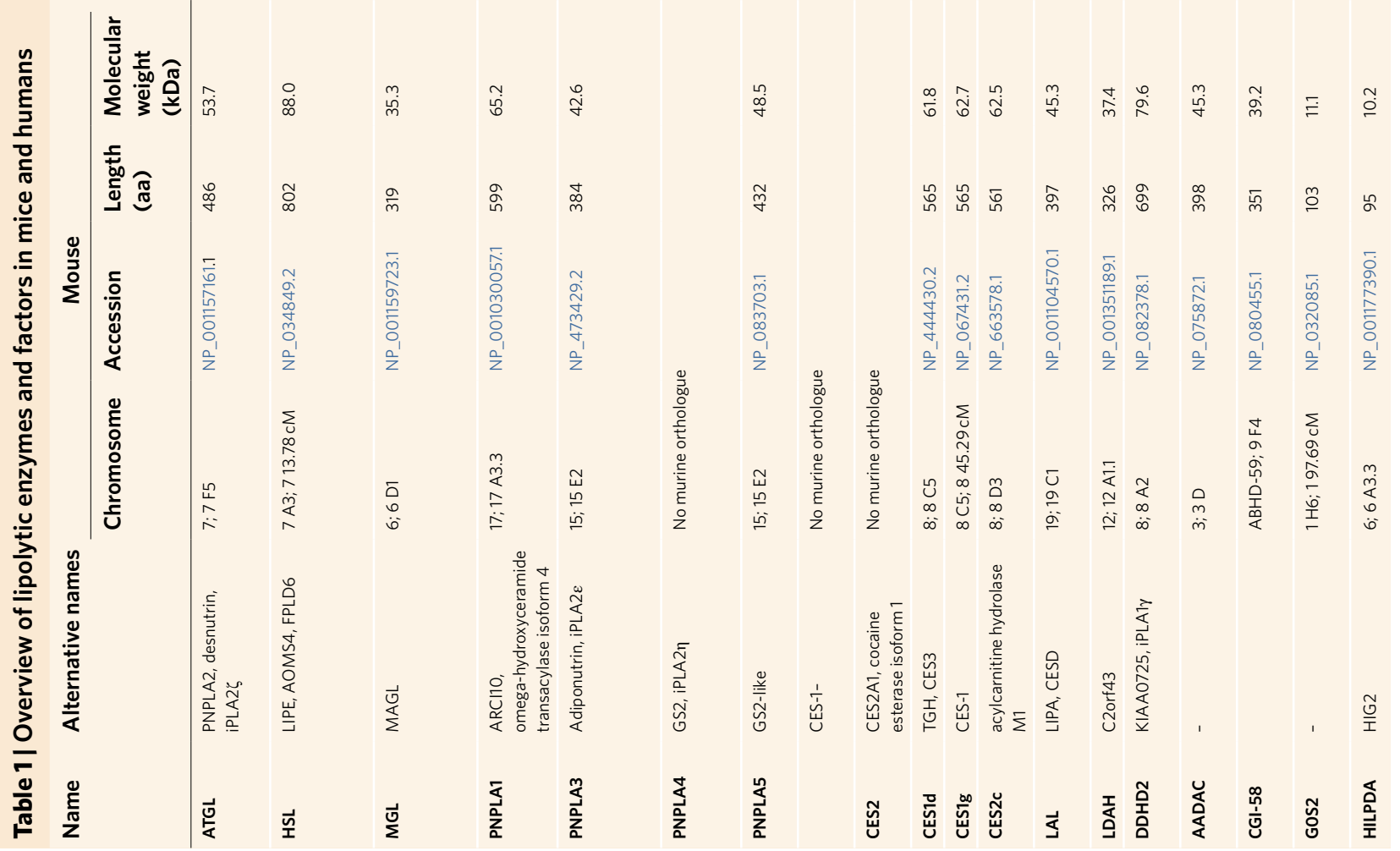


mitochondrial biogenesis and function, and defective respiration, which eventually causes lethality ${ }^{25}$. Restoring ATGL expression in the heart of ATGL-deficient mice rescues the cardiac phenotype, prevents premature lethality ${ }^{25}$ and may therefore provide a potential treatment strategy for people with NLSDM. These initial studies in ATGL-knockout (ATGL-KO) mice highlighted the crucial role of the enzyme for lipolysis not only in adipose tissue, but also in major energy-consuming organs, such as the heart. They also demonstrated that, in addition to its important role for the provision of energy substrates, ATGL-mediated lipolysis also participates in the regulation of major signalling pathways that regulate energy homeostasis. These pathways include insulin signalling ${ }^{26,27}$ and nuclear receptor signalling via PPAR $\alpha\left(\right.$ refs. $\left.^{25,28}\right)$, PPAR $\gamma\left(\right.$ ref. $^{29}$ ) and PPARS (refs. ${ }^{30,31}$ ), as well as protein and histone acetylation and deacetylation processes that affect gene transcription ${ }^{32,33}$. The lipolysis-dependent regulation of PPAR activation involves transcriptional $^{33}$ and post-transcriptional mechanisms ${ }^{34}$.

Hormone-sensitive lipase. Hormone-sensitive lipase (HSL) is a structurally unique member within the large Ser-lipase/esterase family of enzymes in the animal kingdom. In fact, the closest structural relatives of HSL are found in prokaryotes, archaea and plants. The structure of the mammalian LIPE gene, which encodes HSL, as well as the enzyme's function, properties and regulation, were recently extensively reviewed by Recazens et al..$^{35}$. Tissue-specific protein isoforms, ranging from 775 amino acids (in most tissues) to 1,088 amino acids (in testis), result from alternative transcription start sites and exon usage. HSL exhibits broad substrate specificity with highest activity against DGs and cholesteryl esters (CEs), followed by TGs, MGs, retinyl esters and short-chain acyl esters. The enzyme harbours five serine phosphorylation sites, which are targeted by multiple protein kinases and have important regulatory functions affecting enzyme activity (see section on regulation of lipolysis).

Important insights into the physiological role of the enzyme in humans were revealed by clinical characterization of homozygous individuals with HSL deficiency and heterozygous carriers of loss-of-function LIPE gene mutations ${ }^{36,37}$. HSL deficiency manifests in a more benign phenotype than does ATGL deficiency. It is characterized by relatively mild forms of dyslipidaemia, hepatic steatosis, partial lipodystrophy and type 2 diabetes. HSL-deficient adipose tissue consists of small, insulin-resistant adipocytes, which exhibit increased inflammation and impaired glycerol release upon lipolytic stimulation ${ }^{36}$. Partial lipodystrophy results from a downregulation of PPAR- $\gamma$ and its downstream target genes when HSL is lacking, leading to reduced adipogenesis and insulin sensitivity. Notably, HSL also regulates the transcriptional activity of another nuclear receptor, carbohydrate responsive element binding protein $(\mathrm{CHREBP})^{38}$. Independent of its hydrolytic activity, HSL binds to CHREBP and thereby prevents its translocation into the nucleus, reduces target gene expression and leads to insulin resistance. Conversely, blocking HSL binding to CHREBP increases target gene expression and insulin sensitivity ${ }^{38}$. However, the fact that people with reduced or no HSL expression are generally more insulin resistant than are individuals with normal HSL expression ${ }^{36,37}$ suggests that the HSL-mediated regulation of insulin sensitivity via CHREBP is not a predominant regulatory mechanism of insulin sensitivity in humans.

Mice deficient in HSL phenocopy ATGL-deficient mice with PPAR $\gamma$-dependent lipodystrophy in adipose tissue $\mathrm{e}^{5,30,39,40}$, suggesting that the regulation of these nuclear receptors by lipolysis is not enzyme-specific. HSL has a prominent role in DG hydrolysis within the lipolytic cascade as mice lacking HSL accumulate DGs in various tissues ${ }^{6}$. Finally, in contrast to humans, HSL-deficient mice are sterile owing to defective spermatogenesis, sperm motility and fertility $^{5,41}$. The molecular basis for this species-specific difference of enzyme function in spermatogenesis remains to be discovered.
Monoacylglycerol lipase and $\alpha / \beta$ hydrolase domain-6. Monoacylglycerol lipase (MGL) was the first characterized MG hydrolase (Table 1$)^{42,43}$. The enzyme hydrolyses both $s n-1 \mathrm{MG}$ and $s n-2 \mathrm{MG}$, in which FAs are esterified to the terminal or middle hydroxyl group of the glycerol backbone, respectively, to generate glycerol and FAs. Although the preferred substrate for MGL are MGs, the enzyme was also shown to hydrolyse prostaglandin-glycerol esters and FA-ethyl ethers ${ }^{44-46}$. MGL expression is subject to nutritional $^{47}$ and PPAR $\alpha$-dependent regulation ${ }^{48}$, and MGL protein is targeted for proteasomal degradation involving Staphylococcal nuclease and tudor domain-containing 1 (SND1) ${ }^{49}$. To date, no post-translational modifications of the enzyme are known to affect enzyme activity.

In addition to MGL, several other enzymes are reported to hydrolyse MGs. Their physiological impact in vivo is unclear in most cases, with the exception of $\alpha / \beta$ hydrolase containing- 6 (ABHD6). ABHD6 comprises 337 amino acids with an active site composed of S148, D278 and H306. It is localized to the inner leaflet of the plasma membrane and preferentially hydrolyses FAs at the $s n-1$ position over the $s n-2$ position of MGs. ABHD6 also hydrolyses other substrates, including lysophospholipids ${ }^{50}$ and bis(monoacylg lycerol)-phosphate ${ }^{51,52}$. The highest expression levels of ABHD6 are observed in liver, kidney, intestine, ovary, brown adipose tissue and pancreatic beta cells. In some tissues (for example pancreas) and cancer cell lines that have low MGL expression, ABHD6 becomes the main MG hydrolase ${ }^{53}$ and has been associated with the development of insulin resistance ${ }^{50}$ and cancer progression ${ }^{54,55}$.

Since the catabolic pathways of TGs and glycerophospholipids (PLs) converge in the formation of MGs, it is difficult to assign specific phenotypes resulting from enzyme overexpression or deficiency to changes in TG-derived versus PL-derived MGs. MGL deficiency in mice causes MG accumulation in various tissues, minor changes in plasma very-low-density lipoprotein (VLDL) metabolism, impaired intestinal lipid absorption and a moderate protection from diet-induced obesity and hepatic steatosis ${ }^{56-58}$. Most severe accumulation of MGs is observed in brain with high levels of 2-arachidonoylglycerol (2-AG $)^{59,60}$. 2-AG belongs to a class of signalling lipids called endocannabinoids, which act as retrograde neurotransmitters and affect diverse physiological processes. In mice, MGL deficiency ameliorates neuroinflammation and cancer malignancy owing to diminished 2-AG hydrolysis and reduced arachidonic acid availability ${ }^{61-64}$. Pharmacological inhibition or genetic deletion of ABHD6 also increases $s n-1$ and $s n-2$ MG concentrations in different tissues, thereby altering multiple aspects of metabolism and energy homeostasis ${ }^{53,65}$. ABHD6 inhibition induces insulin secretion, adipose tissue browning and brown adipose tissue activation, and exerts neuroprotective and anti-inflammatory effects. The different phenotypes arising from MGL or ABHD6 inhibition remain poorly understood and may be explained by their different cellular localization and expression patterns.

The complex regulation of canonical lipolysis. Energy-substrate demand during food deprivation represents the major driver of lipolysis ('induced lipolysis'). The subsequent release of FAs from white adipose tissue induces a metabolic switch in many energy-consuming tissues from glucose to FA utilization. Simultaneously, the upregulation of hepatic gluconeogenesis and glucose secretion provides glucose to glucose-dependent cells and tissues. Conversely, low lipolytic rates in the fed state ('basal lipolysis') lead to decreased FA and increased glucose utilization in tissues with high energy demand and fat deposition in adipose tissue. The ability of cells and organs to switch between different energy substrates such as FAs and glucose defines their 'metabolic flexibility'. Numerous endocrine, paracrine and autocrine factors, including hormones, cytokines and neurotransmitters, trigger the switch between basal and induced lipolysis by regulating the major 
lipolytic enzymes ATGL and HSL on multiple levels, including gene transcription, post-translational protein modifications and, in the case of ATGL, regulation by enzyme coactivators and inhibitors. The classical activation pathway in adipocytes involves catecholamines, which activate both enzymes ATGL and HSL via hormonal (epinephrine) or sympathetic-neuronal (norepinephrine) stimulation. Other activating hormones and cytokines include glucocorticoids, thyroid hormone, eicosanoids, atrial natriuretic peptides, growth hormone, interleukins, tumour necrosis factor $\alpha$, leptin and many others ${ }^{66}$. Insulin represents the classical inhibitory hormone for ATGL and HSL.

Transcriptional control of ATGL and HSL expression. Regulation of lipase gene transcription is a major mechanism controlling lipolysis (summarized in Fig. 2). Unfortunately, the transcriptional control elements in the promoters of the genes coding for ATGL (Pnpla2) and HSL (Lipe) have not been sufficiently characterized. Evidence suggests that both genes are direct targets for the PPAR family of nuclear receptor transcription factors ${ }^{67-69}$. Other members of the nuclear receptor family, RXR, LXR- $\alpha$ and steroidogenic factor-1, are specific for Lipe and do not regulate Pnpla2 transcription $^{70,71}$. The Lipe promoter also contains a sterol regulatory element rendering Lipe gene expression subject to sterol regulatory element binding proteins (SREBPs) ${ }^{72}$. Several transacting factors that drive adipogenesis, for example, the G/C-box-binding factor specificity protein-1 (SP1), E-box-binding transcription factor-E3 (TFE3) or CEBP $\alpha$, also regulate transcription of Pnpla2 and Lipe $^{67,68,73,74}$.

While catecholamines exert their prolipolytic effects predominantly on the level of enzyme activities, other lipolysis-activating hormones and cytokines act primarily via transcriptional control of lipase expression. For example, growth hormone $(\mathrm{GH})$ induces Pnpla2 transcription via two distinct mechanisms. The predominant pathway involves $\mathrm{GH}$ binding to its receptor and subsequent activation of the transcription factor signal transducer and activator of transcription-5 (STAT5) through Janus kinase-2 (JAK2)-catalysed phosphorylation. Phospho-Stat-5 directly activates Pnpla2 transcription in white and brown adipocytes ${ }^{75,76}$. Consistent with this finding, JAK2 or STAT5 deletion impairs lipase expression ${ }^{75,77}$. Independent of STAT5, GH additionally triggers the mitogen-activated protein (MAP) kinase pathway activating extracellular signal-regulated kinase-1/2 (ERK-1/2). ERK1/2 phosphorylates the $\beta 3$-adrenergic receptor ${ }^{78}$ and $\mathrm{HSL}^{79}$, and promotes the transcriptional downregulation of the ATGL inhibitors G0S2 and fat-specific protein-27 (FSP27; in humans designated cell-death-inducing DNA fragment factor 40/45-like effector C, CIDEC) ${ }^{80,81}$. This combination of effects results in a robust induction of lipolysis. The MAP kinase pathway was recently also shown to activate ERK-3 in response to $\beta$-adrenergic stimulation. This atypical member of the MAP kinase family increases forkhead box protein O-1 (FOXO1)-mediated ATGL transcription and stimulates lipolysis ${ }^{82}$.

Activin $\mathrm{B}^{83}$, growth/differentiation factor-3 (GDF-3) $)^{84}$, myostatin (also called GDF-8) ${ }^{85}$, bone morphogenetic protein (BMP)$4^{86}$ and BMP-7 (ref. ${ }^{87}$ ) belong to the TGF- $\beta$ family of cytokines and growth factors that regulate lipolysis. GDF-3 and activin B bind to activin-receptor-1c (also called activin receptor like kinase 7, Alk7) leading to the phosphorylation of SMAD transcription factors, which in turn, inhibit CEBP $\alpha$ and PPAR $\gamma$ expression and thereby decrease lipase gene transcription ${ }^{67}$. Concomitantly, the Alk7-dependent pathway also downregulates $\beta 3$-adrenergic receptor expression leading to a reduction of catecholamine-induced lipolysis ${ }^{88}$. In contrast to GDF-3 and activin B, myostatin inhibits lipolysis in adipose tissue via binding to activin type-II receptors. Attenuation of lipolysis by myostatin appears to be due to a general impairment of anabolic pathways in lipid metabolism, decreased

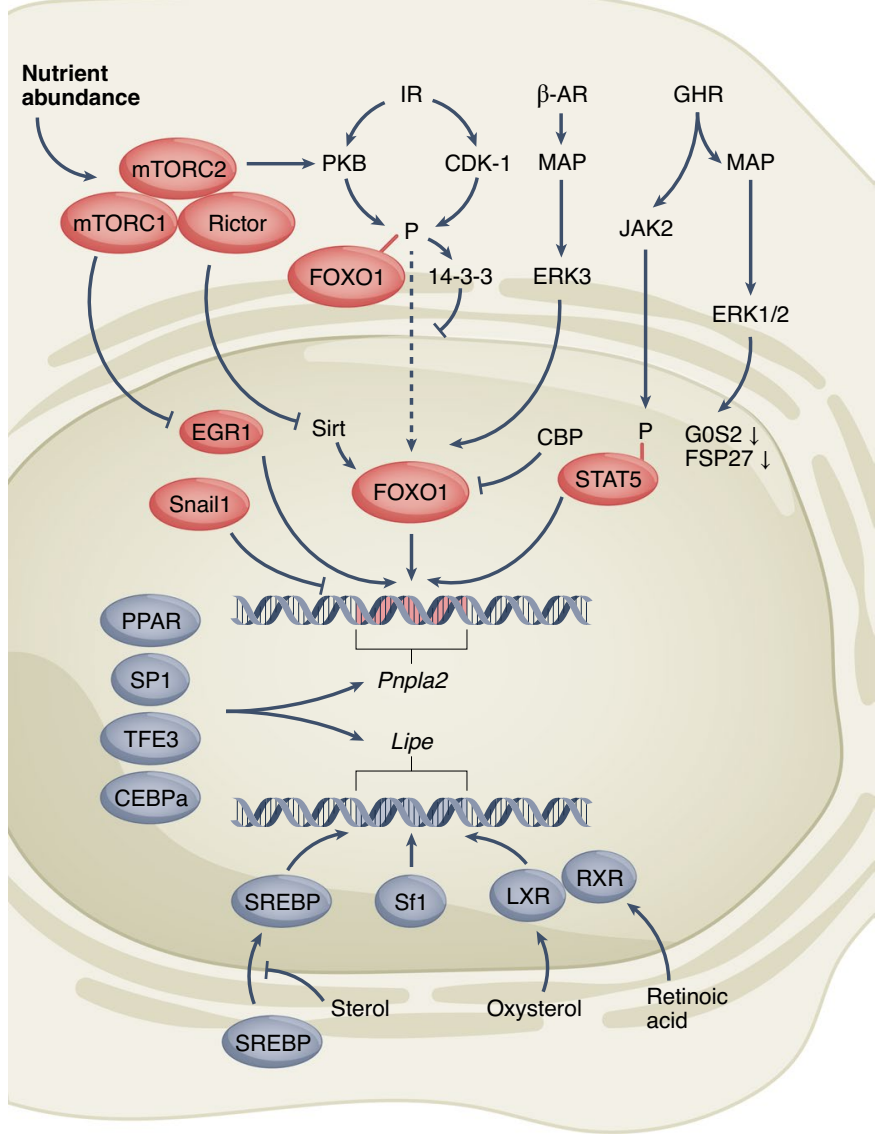

Fig. 2 | Transcriptional regulation of canonical neutral lipolysis. Several transcription factors, including the PPAR family of nuclear receptor transcription factors, SP1, TFE3 and CEBP $\alpha$, regulate the transcription of Pnpla2 and Lipe. Other members of the nuclear receptor family, RXR, LXR- $\alpha$ and SF1, as well as SREBPs are specific for Lipe, but do not regulate Pnpla2 transcription. Pnpla2 expression is activated by FOXO1, STAT5, EGR1, and inhibited by SNAIL1. STAT5 is phosphorylated and activated by JAK2, and is dependent on GHR activation. GHR also activates the MAP kinase pathway involving ERK-1/2 to downregulate GOS2 and FSP27 transcription, which increases ATGL activity. MAP also activates ERK-3 to increase FOXO1-mediated ATGL transcription. On the contrary, IR activation inhibits Pnpla2 transcription by the PKB- and CDK1-catalysed phosphorylation of FOX01, which leads to 14-3-3 protein interaction and cytoplasmic retention of the transcription factor. Moreover, DNA binding of FOXO1 is abrogated by lysine acetylation via cAMP-responsive element binding protein (CBP)/p300. Members of the SIRT family of NAD+-dependent deacetylases reverse this inhibitory effect and restore expression of Pnpla2. Neutral lipolysis is further regulated by mTORC1 and mTORC2, enabling cells to react to nutrient availability. $\mathrm{MTORC} 1$ regulates Pnpla2 transcription by inhibiting EGR1, while mTORC2 inhibits lipolysis by activating PKB-mediated FOXO1 phosphorylation. Rapamycin-insensitive companion of mTOR (Rictor) inhibits SIRT-mediated deacetylation of FOXO1 and Pnpla2 expression through a yet unknown mechanism.

adipocyte differentiation as well as proliferation ${ }^{85,89}$. These observations may explain the findings that blockade of myostatin signalling is associated with decreased fat mass in fish, mice and humans, despite increased ERK1/2-mediated HSL phosphorylation ${ }^{90}$. The molecular mechanisms of other classical prolipolytic inflammatory cytokines, such as tumour necrosis factor- $\alpha(\mathrm{TNF} \alpha)$, interleukin- $1 \beta$ (IL-1 $\beta$ ) or interleukin-6 (IL-6), remain poorly characterized and mostly affect lipolysis by indirect mechanisms ${ }^{91}$. 
Transcription factor FOXO1 is the key factor in insulin-mediated downregulation of Pnpla2 gene expression ${ }^{92}$. FOXO1 binds directly to the promoter of Pnpla2 to induce its expression ${ }^{93}$. The transactivating function of FOXO1 is predominantly controlled by its modification status: phosphorylation determines its intracellular localization and acetylation regulates its activity. Insulin inhibits Pnpla2 transcription by the protein kinase B (PKB)-catalysed phosphorylation of FOXO1, which leads to $14-3-3$ protein interaction and cytoplasmic retention of the transcription factor ${ }^{94}$. In hepatocytes, CDK1-dependent phosphorylation of FOXO1 similarly suppresses ATGL expression by cytoplasmic retention of FOXO1. Consistent with this finding, hepatocyte-specific CDK1 deletion induces ATGL-mediated hepatic fat degradation ${ }^{95}$. In contrast, interaction of 14-3-3 proteins with FOXO1 is inhibited by the AMPK-dependent phosphorylation of Ser22 of FOXO1, which enables translocation of this protein to the nucleus ${ }^{96}$. The other inhibitory post-translational modification of FOXO1, namely lysine acetylation by cAMP-responsive element binding protein (CBP)/ p300, diminishes DNA binding of the transcription factor ${ }^{97}$. Histone deacetylases, including the $\mathrm{NAD}^{+}$-dependent sirtuins (SIRT)-1 and SIRT6, reverse this inhibitory effect and restore expression of target genes, including Pnpla2 (refs. ${ }^{98,99}$ ). A reciprocal feedback is plausible given the fact that SIRT1 regulates ATGL via FOXO1, and ATGL also activates SIRT1, thereby affecting the transcription of genes involved in autophagy ${ }^{32,33}$. In addition to FOXO1, insulin inhibits lipolysis via the Zn-finger transcription factor SNAIL1. In adipocytes, insulin increases SNAIL1 expression, which binds to E2-box sequences in the Pnpla2 promoter and represses its transcription ${ }^{100}$.

Finally, lipolysis is inhibited by the key serine/threonine protein kinase, mechanistic target of rapamycin (mTOR). mTOR is embedded in two larger protein complexes named mTORC1 and mTORC2. mTORC1 activity is predominantly regulated by essential amino acids and induces cell growth and proliferation by the induction of protein, lipid and nucleic acid biosynthesis. mTORC1 inhibition by rapamycin or deletion of the regulatory-associated protein of mTOR (Raptor) induces lipolysis in an ATGL-dependent

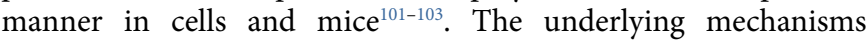
include an upregulation of ATGL transcription by the transcription factor early growth response protein-1 (EGR1) ${ }^{104}$ as well as post-transcriptional mechanisms ${ }^{102}$. $\mathrm{mTORC} 2$ is a major regulator of the insulin/insulin-like growth factor (IGF) signalling pathway by phosphorylating $\mathrm{AKT} / \mathrm{PKB}$, controlling various aspects of carbohydrate and lipid metabolism as well as autophagy and cell survival $^{105}$. mTORC2 inhibits lipolysis in adipose tissue and amplifies the antilipolytic function of insulin by phosphorylating AKT ${ }^{106,107}$. Moreover, and independently of the canonical mTORC2-AKT axis, rapamycin-insensitive companion of $\mathrm{mTOR}$ (Rictor) deletion leads to an induction of lipolysis via SIRT6-mediated deacetylation of FOXO1, and induction of ATGL expression ${ }^{99}$. Further studies are needed to clarify how mTORC2 affects SIRT6 activity.

Regulation of lipases by post-translational modifications. The canonical activation pathway of lipolysis in adipocytes involves the binding of catecholamines to $\beta$-adrenergic G-protein-coupled receptors. Upon hormone binding, the $\alpha$-subunit of the receptor-coupled trimeric $G_{s}$ protein dissociates and stimulates adenylate cyclase, resulting in cAMP synthesis ${ }^{108}$. Very recently, a new G-protein-coupled receptor was identified that constitutively activates adenylate cyclase in brown adipose tissue independently of ligand binding ${ }^{109}$. cAMP activates protein kinase A (PKA), which phosphorylates HSL (at residues S552, S649 and S650) and perilipin-1, a key player in the regulation of lipolysis (at residues S81, S222, S276, S433, S492 and S517) ${ }^{110}$. Phosphorylation results in HSL translocation to the LD and activation of the enzyme's hydrolytic activity. PKA is not the only protein kinase phosphorylating HSL and perilipin-1. Atrial natriuretic peptides via guanyl-cyclase-derived cGMP activate protein kinase $\mathrm{G}$, which phosphorylates both proteins at the same sites as $\mathrm{PKA}^{111}$. HSL is additionally phosphorylated (S600) and activated by ERK1/2 in response to mitogens, growth factors or cytokine signalling via the mitogen-activated protein kinase (MAPK) pathway $^{79}$. Perilipin-1 phosphorylation is required for HSL translocation, but also triggers its dissociation from CGI-58, thereby enabling CGI-58 to interact with ATGL and to activate enzyme activity $^{112}$ (Fig. 3). The central role of perilipin-1 in the regulation of ATGL in humans became evident when Gandotra et al. ${ }^{113}$ reported that mutations in perilipin-1 lead to its inability to bind to CGI-58. This inability of perilipin-1 to buffer CGI-58 during basal lipolysis results in the constitutive hyperactivation of ATGL, unrestrained lipolysis, hyperlipidemia and fatty liver disease $\mathrm{e}^{113,114}$.

In cell types with high oxidation rates, such as hepatocytes or cardiomyocytes, perilipin-5 coordinates the interaction of ATGL with CGI-58. Perilipin-5, unlike perilipin-1, is able to bind both ATGL and CGI-58, but the binding is mutually exclusive $e^{114,115}$. According to current understanding, two perilipin-5 molecules bound to ATGL and CGI-58, respectively, need to oligomerize to enable ATGL activation ${ }^{116}$. Perilipin-5 interaction with ATGL depends on the PKA-mediated phosphorylation of S155 in perilipin-5 (refs. ${ }^{117,118}$ ). Interestingly, hormone-stimulated ATGL binding to perilipin-5 also promotes the translocation of FAs to the nucleus, where they act as allosteric activators of SIRT1 (ref. ${ }^{33}$ ). This $\mathrm{NAD}^{+}$-dependent protein deacetylase subsequently deacetylates specific transcription factors, including PGC-1, to increase the expression of OXPHOS genes. Overall, however, the impact of perilipin-5 on lipolysis appears more modulatory than necessary, since periplipin-5-deficient mice exhibit elevated lipolysis ${ }^{119}$, while overexpression of perilipin-5 leads to reduced lipolysis and a steatotic phenotype in transgenic mice ${ }^{120}$. In contrast to perilipin-1 and perilipin-5, the impact of perilipin-2, perilipin-3 and perilipin-4 on regulation of hormone-stimulated lipolysis is not well understood and may be less prominent ${ }^{110,121}$.

Insulin and IGFs represent the predominant inhibitory hormones of lipolysis. They diminish both activity and gene expression of lipolytic enzymes ${ }^{122}$. The dominant pathway to inhibit enzyme activities involves the deactivation of the cAMP-PKA-pathway. Insulin, via the classical phosphatidylinositol-3 (PI3)-kinase-dependent signalling pathway, stimulates phosphoinositide-dependent kinase-1 (PDK1) and AKT/PKB, which activates phosphodiesterase 3B (PDE3B), resulting in the hydrolysis of CAMP, inactivation of PKA and consecutive downregulation of HSL and perilipin phosphorylation $^{123}$. Interestingly, this process requires PDE3B interaction with ABHD15 (ref. ${ }^{124}$ ), but is independent of PDE3B phosphorylation by $\mathrm{PKB}^{123}$. Another mechanism inhibiting lipolysis involves the activation of $\alpha$-adrenergic receptors coupled with $\mathrm{G}_{\mathrm{i}}$-proteins by adenosine, which inhibits adenylate cyclase and cAMP synthesis ${ }^{125}$ (Fig. 3).

High cellular AMP concentrations during fasting or prolonged exercise induce ATGL gene transcription via AMPK dependent phosphorylation of FOXO1 (see section on transcriptional control). Whether AMPK also activates lipolysis by directly phosphorylating ATGL and HSL remains controversial. Both enzymes are AMPK phosphorylation targets (ATGL-S406 and HSL-S554). However, while AMPK-catalysed ATGL phosphorylation increases its activity $^{12}$, HSL phosphorylation has an inhibitory effect. Whether AMPK stimulates or inhibits lipolysis may therefore strongly depend on specific experimental conditions leading to different results in various studies $^{126}$. Also, the finding that adipose-specific deletion of AMPK has no effect on TG hydrolysis argues against a prominent role of AMPK in the regulation of lipolysis ${ }^{127}$. Notably, however, a recent report demonstrated that lipolysis activates AMPK $^{128}$. Under hormonal stimulation, excessive lipolysis leads to increased FA re-esterification within a futile cycle of TG hydrolysis and resynthesis. This process is quite energy demanding and results in accumulated AMP and the activation of AMPK. This, in turn, causes 


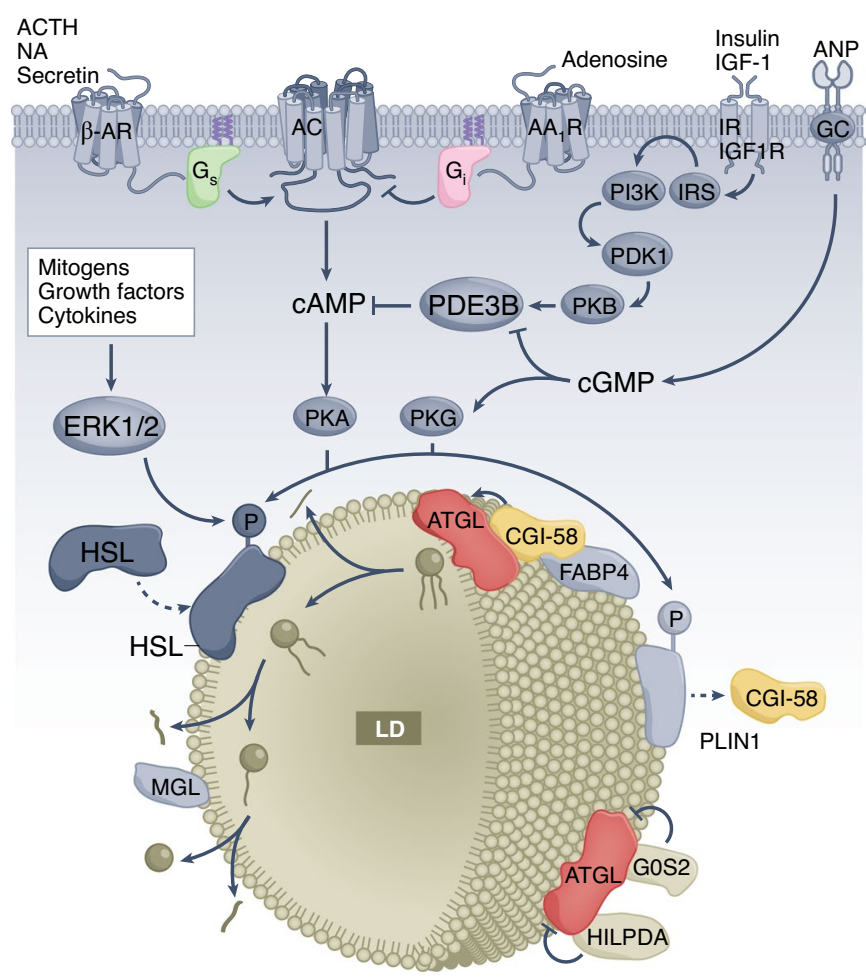

Fig. 3 | Post-translational regulation of canonical neutral lipolysis. Lipolysis is stimulated by activation of $\beta$-adrenergic $\mathrm{G}$-protein-coupled receptors ( $\beta-A R)$. Binding of noradrenalin (NA), adrenocorticotropic hormone (ACTH) or secretin leads to dissociation of the receptor-coupled trimeric $G_{s}$ protein and stimulation of adenylate cyclase (AC), resulting in CAMP synthesis. CAMP activates protein kinase $A(P K A)$, which phosphorylates HSL and PLIN1. HSL translocates to LDs upon phosphorylation by PKA, protein kinase G (PKG) or ERK1/2. PLIN1 sequesters CGI-58, which is released upon PKA- or PKG-mediated phosphorylation to stimulate ATGL activity. PKG is activated by atrial natriuretic peptides (ANPs) via GC-derived cGMP. Enzymatic activity of ATGL is enhanced by CGI-58 and inhibited by GOS2 and HILPDA. FABP4 interacts with CGI-58 to further stimulate ATGL activity. Lipolysis is inhibited by insulin or insulin-like growth factor-1 (IGF-1) via insulin receptor or IGF receptor. Ligand binding subsequently activates insulin receptor substrate-1, phosphatidylinositol-3-kinase, PDK1 and PKB, which activates PDE3B, resulting in the hydrolysis of CAMP. Lipolysis is also inhibited by adenosine, which decreases CAMP levels by activation of $\alpha$-adrenergic receptors $\left(A A_{1} R\right)$ coupled with $G_{i}$ proteins, inhibiting adenylate cyclase and cAMP synthesis.

mTORC1 inactivation and cellular growth arrest, a mechanism that may explain the inhibitory effect of lipolysis on cancer cell growth $^{128,129}$. These results are also consistent with the finding that enhancing AMPK activity by an AMPK-stabilizing peptide reduces adipose tissue atrophy in cancer-associated cachexia ${ }^{130}$.

Peptide-coregulators of ATGL. CGI-58 (ABHD-5). LD-bound ATGL requires a protein coactivator called comparative gene identification-58 (CGI-58) or $\alpha / \beta$ hydrolase domain-containing-5 (ABHD-5) for full enzyme activity ${ }^{9}$. Human CGI-58 is a protein of 349 amino acids that belongs to a family of 17 ABHD proteins, most of which are lipid hydrolases ${ }^{131}$. CGI-58 is an exception because it lacks the nucleophilic amino acid residue in the catalytic triad of the active site that is essential for functional hydrolases ${ }^{132}$. Unfortunately, molecular details concerning the actual activation mechanism are still unknown and will likely require three-dimensional structural information for both proteins. Phylogenetic and mutational analyses revealed that the highly conserved amino acid residues R299 and G328 in human CGI-58 are essential for ATGL activation ${ }^{133}$. Importantly, the Grannemann group developed a small-molecule inhibitor that disrupts the interaction of perilipin-1 and CGI-58. In the presence of this inhibitor, CGI-58 constitutively activates ATGL even in the absence of hormonal stimulation, which leads to unrestrained TG degradation ${ }^{134}$.

While global ATGL-KO mice die at the age of about 12 weeks from severe cardiomyopathy, CGI-58-deficient mice die within 24 hours of birth owing to trans-epithermal water loss and desiccation caused by a severe epidermal skin defect ${ }^{135}$. Absence of this phenotype in ATGL-deficient humans and mice argues strongly for an ATGL-independent epidermal function for CGI-58. In humans, mutations in the gene for CGI-58 cause an autosomal recessive skin disease designated NLSD with Ichthyosis (NLSDI) ${ }^{21,136}$. Since its original discovery in the 1970s, more than 100 cases of NLSDI have been reported. The disease is characterized by the accumulation of TGs in many tissues and severe ichthyosis ${ }^{137}$. Independent of ATGL, CGI-58 in keratinocytes interacts with and activates PNPLA1 transacylase activity driving acylceramide synthesis in the skin (see section on PNPLA1) ${ }^{138,139}$. CGI-58 also interacts with PNPLA3, the closest relative of ATGL within the PNPLA family (see below in section on PNPLA3) ${ }^{140}$. Other ATGL-independent functions of CGI-58 include an acyltransferase- ${ }^{141}$ and HDAC4-specific protease activity ${ }^{142}$. Whether these activities contribute to normal skin barrier function and the pathogenesis of NLSDI is currently not known.

G0S2. G0/G1 switch gene-2 (G0S2) is a 106-amino-acid protein that was originally described as a cell-cycle regulator mediating G0/G1 re-entry ${ }^{143}$. Like CGI-58, G0S2 turned out to be a multifunctional protein involved in cell proliferation, mitochondrial ATP production, apoptosis and cancer development ${ }^{144}$. Its best-characterized function, however, relates to its interaction and inhibition of ATGL $^{145,146}$. Liu and colleagues elegantly demonstrated that G0S2 in mice and humans interacts via a hydrophobic stretch within the patatin domain of ATGL, thereby suppressing enzyme activity ${ }^{147}$. Non-cooperativity of G0S2 and CGI-58 suggest that the coregulators bind to ATGL at different sites. Oberer and colleagues developed a 33-amino-acid peptide ranging from K20 to A52 of human G0S2, including the hydrophobic ATGL interaction region, which inhibited ATGL with similar potency as full-length G0S2 (ref. ${ }^{148}$ ). Both full-length G0S2 and the G0S2-derived peptide noncompetitively inhibit ATGL with a half-maximal inhibitory concentration $\left(\mathrm{IC}_{50}\right)$ in the nanomolar range. G0S2 specifically inhibits ATGL but fails to inhibit other lipid hydrolases of the PNPLA family or lipolytic enzymes ${ }^{148}$. In addition to its antilipolytic function, G0S2 may also have lysophosphatidyl-acyltransferase activity ${ }^{149}$.

G0S2 protein abundance is highest in adipose and relatively low in most other tissues. Fasting/feeding and nuclear receptor transcription factors PPAR $\alpha$ and LXR $\alpha$ regulate G0S2 mRNA expres$\operatorname{sion}^{150,151}$. Consistent with the strong inhibitory effect of G0S2 on ATGL activity, its tissue-specific overexpression leads to steatosis in cardiac muscle or liver in mice ${ }^{152,153}$. Somewhat unexpectedly, G0S2-deficient mice exhibited a relatively modest phenotype with a slight increase in lipolysis and minor alterations in lipid and energy metabolism, as well as adipose tissue morphology ${ }^{154,155}$. The effect of G0S2 deficiency was more pronounced in the liver, resulting in decreased liver fat and resistance to high-fat-diet-induced hepatosteatosis $^{156}$. The relatively low expression levels of G0S2 in mice may explain the lack of a major phenotype upon its deletion.

HILPDA. Hypoxia-induced lipid droplet-associated protein (HILPDA), also called hypoxia-induced gene-2 (HIG2), is a G0S2-related peptide of 63 amino acids that also inhibits ATGL 
activity. HILPDA was originally identified as an LD-binding protein that is highly expressed in response to hypoxia ${ }^{157}$. The promoter of the Hilpda gene harbours a number of hypoxia-responsive elements that are targeted by the transcription factors HIF-1 and HIF-2 (ref. ${ }^{158}$ ). Like GOS2, Hilpda is a PPAR $\alpha$ target gene ${ }^{159}$. HILPDA is abundantly expressed in immune cells, adipose tissue, liver and lung ${ }^{160}$. The protein binds to LDs and interacts with the $\mathrm{N}$-terminal region of ATGL, thereby inhibiting ATGL activity in the absence or presence of CGI-58 (refs. ${ }^{161,162}$ ). Compared with G0S2, however, human HILPDA is a much less potent ATGL inhibitor ${ }^{163}$. Independently of its effects on ATGL, murine HILPDA also interacts with the TG-synthesizing enzyme diacylglycerol-acyltransferase-1 (DGAT1) and promotes lipid synthesis in hepatocytes and adipocytes $^{164}$. Despite these pronounced activities of HILPDA in vitro, the in vivo consequences of its deficiency in adipose tissue are very moderate. HILPDA deficiency affected neither plasma FA, glycerol or TG concentrations nor adipose tissue mass during fasting or cold exposure, apparently ruling out the possibility that HILPDA is a crucial regulator of lipolysis ${ }^{165,166}$. The generation of double-knockout mouse lines may clarify whether the benign phenotype of G0S2 or HILPDA deficiency results from mutual compensatory functions.

Other regulatory proteins of lipolysis. Lipase-protein interaction studies revealed a large number of factors that interact with ATGL, HSL or their respective coregulators. In addition to the already mentioned factors (ABHD-5, G0S2, HILPDA, ATGL-trafficking proteins, perilipins and CHREBP), at least a dozen factors have been described to affect lipolysis by direct lipase or coregulator binding. An overview of these factors was recently published by Hofer et al. ${ }^{167}$. They include the ATGL regulatory factors FSP27, pigment epithelium-derived factor (PEDF) and 14-3-3 proteins or the HSL interaction partners fatty acid binding protein-4 (FABP4), vimentin and cavin-1. FABP4 also interacts with CGI-58 and plays an important role in the export of lipolysis-derived FAs or their transport to the cell nucleus ${ }^{34,168,169}$. Taken together, the lipolytic machinery represents a highly complex system composed of numerous factors, which we refer to as 'lipolysome'.

\section{Canonical enzymology of acid lipolysis}

The only known neutral lipid hydrolase which is active under acidic conditions in lysosomes is LAL. This enzyme, originally discovered in 1968 (ref. ${ }^{170}$ ), is responsible for the degradation of CEs, TGs, DGs and retinyl esters ${ }^{171-173}$ from lipoproteins and autophagosomes after their lysosomal uptake. LAL, encoded by the Lipa gene, is highly glycosylated and ubiquitously expressed, with highest levels observed in hepatocytes and macrophages. Several transcript variants of LAL have been described, of which a 288 -amino-acid, $46-\mathrm{kDa}$ protein exhibits the highest enzymatic activity ${ }^{174}$. The three-dimensional structure of the human enzyme was recently solved and revealed strong structural similarities to gastric lipase, another member of the acid lipase family ${ }^{175}$. Regulation of LAL activity is less complex than that of neutral lipases and involves primarily transcriptional mechanisms. Established transcription factors that activate LAL expression include PPARs, FOXO1 and the E-box transcription factors TFEB and TFE3 (ref. ${ }^{176}$ ).

In addition to LAL's lysosomal localization, small amounts of the enzyme are secreted via the classical secretory pathway into the blood $^{177}$. Additionally, LAL is released from cells into the interstitium by a mechanism called exophagy, where the lysosomal membrane fuses with the plasma membrane, liberating the cargo ${ }^{178}$. The function of LAL (with a $\mathrm{pH}$ optimum of 4.5-5) outside lysosomes remains uncertain, but the enzyme may be able to hydrolyse lipids of aggregated or oxidized low-density lipoprotein (LDL) in an acidic extracellular microenvironment ${ }^{179,180}$. Conversely, cells can also internalize extracellular LAL. Enzyme exchange among different cell types and tissues explains the relatively mild phenotype of hepatocyte-specific LAL-KO mice ${ }^{181}$ and represents a potential treatment for people with Wolman's disease by enzyme replacement therapy $^{182}$ (see below).

LAL reaction products include non-esterified cholesterol and FAs. Cholesterol is subsequently released from lysosomes by an NPC1-dependent process and suppresses cholesterol de novo synthesis by multiple mechanisms ${ }^{183,184}$. Excess cholesterol is re-esterified and stored as CE in cytoplasmic LDs. The export mechanism for FAs is not well understood. After their liberation, they contribute to hepatic VLDL synthesis ${ }^{185}$, induce the alternative activation of macrophages ${ }^{186}$, represent precursors for highly bioactive lipid mediators ${ }^{187}$ and drive thermogenesis in brown adipose tissue ${ }^{188}$.

The role of lysosomes in the degradation of cargo derived from various endocytosed lipoproteins was recognized many decades ago. This function was extended when, in 2009, lipophagy was identified as a distinct form of autophagy and a quantitatively relevant mechanism for the hydrolysis of TGs and CEs in hepatocytes and macrophages ${ }^{189-191}$. Three types of autophagic pathways contribute to TG degradation: macrolipophagy, microlipophagy, and chaperone-mediated autophagy (CMA) ${ }^{192}$ (Fig. 4). During macrolipophagy, autophagosomes sequester and engulf parts of LDs and subsequently fuse with lysosomes to form autolysosomes ${ }^{189}$. In contrast, microlipophagy does not involve enclosure of LD components within autophagosomes. Instead, a direct flux of lipids occurs during transient docking of lysosomes to LDs by a 'kiss and run' mechanism ${ }^{193}$. Microlipophagy is a well-established process in yeast but has only recently been discovered in mammalian cells ${ }^{194}$. Interestingly, knockdown of ATGL in hepatocytes leads to reduced microlipophagy, indicating a connection between microlipophagy and neutral lipolysis ${ }^{194}$. A plausible explanation for this dependency is that ATGL activity reduces $\mathrm{LD}$ size, thereby rendering LDs more accessible for microlipophagy $y^{194,195}$. ATGL also plays an important role in CMA, in which the autophagosomal degradation of perilipins allows ATGL to access the surface of LDs and thereby stimulates lipolysis ${ }^{196}$. Heat shock protein 70 (HSP70) directly interacts with perilipin- 2 and perilipin- 3 on LDs by recognizing $i » ~ ¿$ a pentapeptide motif ${ }^{197}$. It subsequently delivers them to lysosomes and facilitates their uptake and degradation, mediated by lysosome-associated membrane 2 (ref. ${ }^{198}$ ). Mutation of Hsp70 binding motifs on perilipins leads to reduced CMA and LD accumulation in cultured cells and mouse livers in vivo, despite unaltered macroautophagy ${ }^{196}$.

LAL deficiency in mice leads to massive accumulation of CEs and TGs in the liver, intestine, adrenal glands and macrophages ${ }^{199,200}$. In humans, complete absence of LAL activity also provokes severe hepatosteatosis and hepato-splenomegaly. Unlike the murine model, however, the human deficiency, known as Wolman disease, is lethal within the first year after birth ${ }^{201}$. A more benign variant of the disease is called cholesteryl ester storage disease (CESD). People with CESD often, but not always, show some remnant LAL activity (1-10\% of normal) and, depending on the severity of the disease, can reach a normal life expectancy ${ }^{202}$. People with CESD have a higher risk for atherosclerosis and coronary heart disease ${ }^{203}$. This phenotype is explained by increased lysosomal retention of CE in macrophages owing to low LAL activities leading to insufficient suppression of cholesterol de novo synthesis and foam-cell formation $^{190}$. Several GWAS studies identified common polymorphisms in the Lipa gene that associate with cardiovascular diseases ${ }^{204}$. However, their impact on LAL function remains controversial.

\section{Noncanonical enzymes and mechanisms of TG mobilization}

The canonical lipases ATGL, HSL, MGL and LAL are the best-characterized enzymes with regard to hydrolysis of cytoplasmic TG stores. In adipose tissue, ATGL and HSL account for more than $90 \%$ of TG hydrolysis ${ }^{205}$, rendering the existence of other 


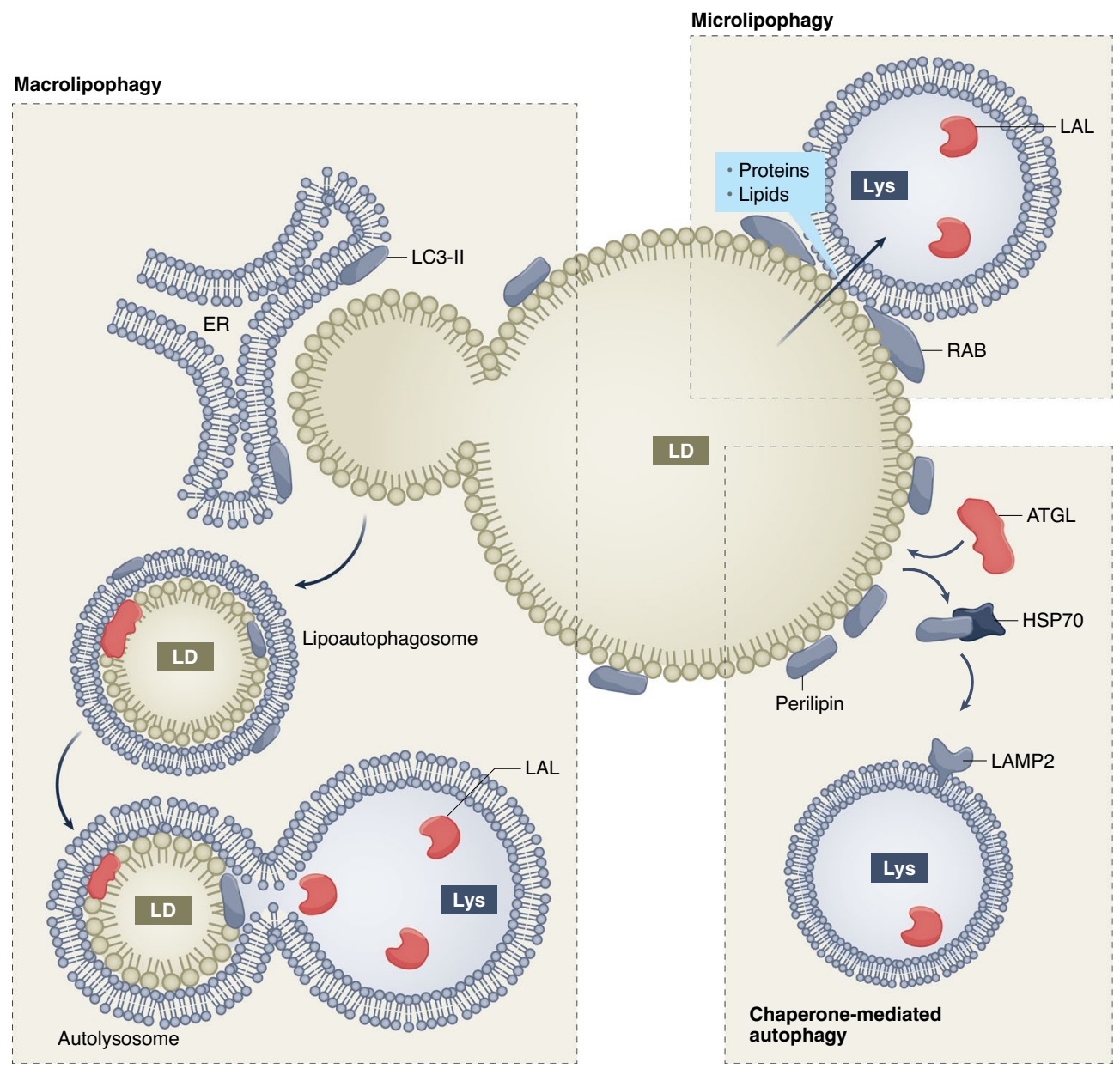

Fig. 4 | Autophagy and acid lipolysis. Three types of autophagic pathways contribute to the degradation of cytosolic LDs. Macrolipophagy involves the microtubule-associated protein 1A/1B-light chain 3 (LC3-II) dependent engulfment of parts of the LDs by ER membranes to form lipoautophagosomes which subsequently fuse with lysosomes to autolysosomes. During microlipophagy, Ras-related in brain (RAB) proteins facilitate the flux of lipids and proteins from $L D$ s to the lysosome. Lysosomal acid lipase ( $L A L)$ is the only known lipase capable of hydrolysing neutral lipids under acidic conditions. Independent of LAL, chaperone-mediated authophagy facilitates a HSP70-mediated transfer and lysosome-associated membrane 2 (LAMP2) dependent lysosomal uptake and degradation of perilipins to increase the accessibility of cytosolic lipases to LDs.

major lipases unlikely. In non-adipose tissues, however, substantial TG hydrolase activities are observed even in the absence of ATGL and HSL. In addition to a significant contribution of acid lipolysis, several alternative neutral lipases of diverse protein families have been connected to TG catabolism in the past decade (summarized in Table 1).

PNPLA family members. Although the critical role of ATGL in lipolysis is undisputed, the distinct biochemical functions of its most closely related family members-PNPLA1, PNPLA3, PNPLA4 and PNPLA5-remain equivocal. The presence of an $\alpha / \beta$ hydrolase fold and a catalytic dyad with an active site serine embedded in a GXSXG consensus sequence provide these proteins with the structural prerequisites to act as lipid hydrolases. While an unambiguous assignment of their primary physiological substrates is still missing, some of these enzymes are directly involved in disease development.

PNPLA1. PNPLA1 is a 446-amino-acid protein specifically expressed in differentiated keratinocytes of the $\operatorname{skin}^{206,207}$. It is an established causative gene for autosomal recessive congenital ichthyosis (ARCI), which is characterized by a severe defect in the development of the epidermal corneocyte lipid envelope (CLE) and the transepithelial water barrier in the skin in humans and $\operatorname{dogs}^{208}$.
The clinical presentation essentially phenocopies the deficiency of CGI-58 in the skin ${ }^{135}$, arguing for a common involvement of both proteins in the formation of the CLE. PNPLA1 is a transacylase that specifically transfers linoleic acid from TG to $\omega$-hydroxy ceramide, thus giving rise to $\omega$-O-acylceramides ${ }^{138,207}$. These skin-specific lipids are essential for the generation of the CLE and an intact skin permeability barrier. Transacylation of FAs requires a hydrolysis reaction that is coupled with an esterification reaction. CGI-58 interacts with PNPLA1 and recruits the enzyme onto cytosolic LDs where PNPLA1 utilizes TG-derived FAs for $\omega$-hydroxy ceramide acylation $^{138,139}$. PNPLA1 mutations leading to ARCI may additionally impair autophagy, arguing for a potential role of PNPLA1 in lipophagy-mediated degradation of $\mathrm{LDs}^{209}$.

PNPLA3. PNPLA3 (also named adiponutrin or calcium-independent phospholipase-A2 $\varepsilon$ ) comprises 481 amino acids, is structurally closely related to ATGL (46\% sequence homology), and highly abundant in white and brown adipose tissue of mice. In humans, PNPLA3 is less abundant in adipocytes, but highly expressed in hepatocytes ${ }^{210}$. Key transcription factors responsible for the expression of PNPLA3 include CHREBP in response to carbohydrates and SREBP1c in response to insulin ${ }^{211,212}$. PNPLA3 localizes to $\mathrm{LDs}^{213}$ and exhibits various enzymatic activities including TG-, DG-, 
MG- and retinyl ester hydrolase activity, PLA $_{2}$ activity and transacylase activity ${ }^{8,214-216}$. It remains unclear which of these activities are physiologically relevant in adipose tissue and in the liver ${ }^{217}$.

The fact that PNPLA3-KO mice have essentially no abnormal phenotype with normal plasma and hepatic TG concentrations ${ }^{218,219}$ argued against a major role of PNPLA3 in lipid homeostasis. This view changed dramatically when Hobbs and colleagues reported that a single amino acid exchange at position 148 from isoleucine to methionine in PNPLA3 (p.I148M) strongly associates with NAFLD $^{220}$. This association was replicated in numerous studies and extended to associations of the mutation with steatohepatitis, fibrosis, cirrhosis and hepatocellular carcinoma ${ }^{217}$. The I148M variant is frequent in populations of Hispanic descent (up to $50 \%$ of individuals), African Americans and Caucasians and is considered a key player in the pathogenesis of liver disease ${ }^{220}$.

Important progress concerning the function of PNPLA3 was achieved by recent studies suggesting that excess PNPLA3 on the surface of LDs competes with ATGL for its coactivator CGI-58 (refs. ${ }^{140,221}$ ). PNPLA3-I148M has higher affinity to CGI-58 than does wild-type PNPLA3 (ref. ${ }^{140}$ ). According to the current understanding, the high affinity of PNPLA3 for CGI-58 leads to a 'coactivator steal' since PNPLA3 retains CGI-58, keeping it from binding to ATGL. This leads to reduced ATGL activity, which may explain the fatty liver disease in people carrying the variant. Additionally, the I148M variant may promote increased TG synthesis via a transacylation reaction ${ }^{216}$. Finally, PNPLA3-I148M's resistance to proteasomal $^{222}$ and autophagy-dependent ${ }^{223}$ protein degradation, compared with that of wild-type PNPLA3, potentially amplifies the impact of the mutant protein on lipid homeostasis.

PNPLA4. PNPLA4 was originally identified as gene sequence 2 (GS2) in the human genome ${ }^{224}$ and is also found in other mammalian species but not in mice ${ }^{225}$. The PNPLA4 gene is located on the $\mathrm{X}$ chromosome between the genes encoding steroid sulfatase and Kallmann Syndrome-1. The human PNPLA4 protein comprises 253 amino acids and is expressed in numerous tissues, including adipose tissue, skeletal and cardiac muscle, kidney, liver and skin $^{225,226}$. Similar to PNPLA3, various enzymatic activities have been attributed to PNPLA4, including TG and retinyl ester hydrolase, phospholipase and transacylase activities ${ }^{8,225,226}$. Genetic analyses have suggested that PNPLA4 is involved in the development of two rare congenital disorders: combined oxidative phosphorylation deficiency (COXPD) and X-linked intellectual disability ${ }^{227,228 .}$ COXPD arises from a hemizygous nonsense mutation resulting in a C-terminally-truncated protein (R187ter) and defective assembly of complexes I, III and IV of the respiratory electron transport chain. Whether the enzymatic activity of PNPLA4 is involved in the pathogenesis of COXPD is unknown. Fortunately, small-molecule inhibitors have recently been developed that may help to elucidate the biochemical function of PNPL4 and its role in (patho-) physiology 229 .

PNPLA5. PNPLA5 (also named GS2-like) is a 429-amino-acid protein that is ubiquitously expressed and, unlike PNPLA4, is present in both mice and humans ${ }^{210}$. Its expression is induced during adipocyte differentiation and in leptin-deficient ob/ob mice, and is inhibited by fasting 225 . PNPLA5 exerts hydrolytic activities towards multiple lipid substrates, including TGs and retinyl esters, but has also been shown to exhibit transacylase activity 225,230 . Notably, PNPLA5-dependent hydrolysis of LD-associated TGs has been suggested to affect autophagosome biogenesis ${ }^{231}$. Furthermore, rare variants of PNPLA5 strongly associate with LDL cholesterol levels in humans ${ }^{232}$. To date, it remains unclarified whether the lipid hydrolase/transacylase activity or its participation in lipophagy has a functional role in the regulation of plasma LDL cholesterol levels.
Carboxyl esterase family members involved in lipolysis. Mammalian carboxylesterases (CESs) belong to a multigene, $\alpha / \beta$-hydrolase fold superfamily encoding 6 human and 20 mouse paralogs. They catalyse the hydrolysis of a wide range of endogenous substrates and xenobiotics ${ }^{233}$. CES family members that exhibit neutral TG hydrolase activity include human CES1 (also called human cholesterylesterhydrolase-1, hCEH) and CES2, and mouse Ces1d (also called Ces3 or TG hydrolase-1), Ces1g (also called Ces1 or esterase-X) and Ces1c. The previously confusing nomenclature of human and murine CES enzymes has recently been revised for more clarity ${ }^{234}$.

Human and mouse carboxylesterases 1. The carboxylesterase 1 (CES1) gene in the human genome encodes a $62-\mathrm{kDa}$ protein with high abundance in liver and intestine and lower abundance in kidney, adipose tissue, heart and macrophages ${ }^{233,235}$. The active site of the monomeric, dimeric or trimeric enzyme consists of a catalytic triad within an $\alpha / \beta$-hydrolase fold ${ }^{235}$. CES1 preferably hydrolyses CEs and TGs ${ }^{236,237}$. Hepatocyte-specific overexpression of human CES1 in transgenic mice increases hepatic TG hydrolase activity; lowers TG, FA and cholesterol content; and reduces reactive oxygen species (ROS), apoptosis and inflammation, which cumulatively protect mice from western-diet- or alcohol-induced steatohepatitis $^{238}$. Both hepatocyte- ${ }^{239}$ and macrophage-specific ${ }^{240}$ overexpression of CES1 in mice decrease atherosclerosis susceptibility in LDL-receptor-deficient mice and, consistent with this finding, treatment of THP-1 macrophages with a CES1 inhibitor caused accumulation of $\mathrm{CE}^{241}$. Another study, however, failed to observe neutral CE hydrolase activity of recombinant CES1 and saw no effects of CES1 overexpression or silencing on cellular cholesterol/ CE homeostasis ${ }^{242}$. Hence, the role of human CES1 in lipid metabolism remains controversial.

Murine Ces1d (also termed triacylglycerol hydrolase-1 (Tgh-1) or Ces3) is a TG hydrolase with $74 \%$ sequence identity to human CES1. Ces1d is highly expressed in adipose tissue and liver ${ }^{243}$ where it localizes to the lumen of the $\mathrm{ER}^{244}$. In adipose tissue, Ces1d is additionally associated with LDs and may contribute to basal lipolysis ${ }^{245,246}$. In mouse hepatocytes, transgenic overexpression or pharmacological inhibition of Ces1d increased or decreased VLDL assembly and secretion, respectively ${ }^{247-249}$. In accordance with these findings, liver-specific and global Ces1d deficiency in mice lowers VLDL production and plasma TG and CE concentrations ${ }^{250,251}$. Despite strong evidence for a role of Ces1d in hepatic VLDL assembly and secretion, it remains unclear how an enzyme residing in the lumen of the ER actually contributes mechanistically to lipoprotein synthesis. Interestingly, while global Ces1d deficiency leads to TG accumulation in isolated hepatocytes, conditional Ces1d knockout in liver cells does not. In fact, they are actually protected from high-fat-diet-induced hepatic steatosis ${ }^{251,252}$. The protective effect of Ces1d deficiency in the liver might be due to reduced FA-synthase activity and increased hepatic FA oxidation ${ }^{250,252}$. Moreover, mice with global, but not liver-specific, Ces1d deficiency exhibit improved insulin sensitivity and glucose tolerance ${ }^{250,251}$. The recent finding that Cesld deficiency does not affect CE hydrolysis or bile-acid synthesis in mice ${ }^{253}$ argues against an important role for CES1 enzymes in cholesterol homeostasis (see previous paragraph).

The second murine ortholog to human CES1 with established TG hydrolase activity is Ces1g. This enzyme is mainly expressed in liver and shows $76 \%$ sequence homology with Ces1d. Overexpression of Ceslg increases TG hydrolase activity and reduces TG content in cultured rat hepatoma cells and livers of transgenic mice $e^{254,255}$. Conversely, global- and liver-specific Ces1g-KO mice exhibit hepatic steatosis and hyperlipidemia ${ }^{255,256}$. Restoration of hepatic Ces1g expression reverses hepatic steatosis, hyperlipidemia and insulin resistance in global Ces1g-deficient mice ${ }^{257}$. Several studies 
suggest that the lipid phenotype observed in Ceslg-deficient mice results from diminished FA signalling to restrain SREBP1c activation, leading to reduced FA oxidation and increased de novo lipogenesis ${ }^{255-257}$.

Human and mouse carboxylesterases 2. Human CES2 is a monomeric $62-\mathrm{kDa}$ protein that shares $47 \%$ amino acid sequence identity with CES1 and 71\% homology with murine ortholog Ces2c. CES2 preferably hydrolyses esters with a large alcohol group and a small acyl group, and as for Ces $2 c$, TG and DG hydrolase activities have been reported ${ }^{258,259}$. CES2 is abundantly expressed in the small intestine, colon and liver and is decreased in mice and humans with obesity and NAFLD ${ }^{235,258,259}$. Adenoviral overexpression of human CES2 in the liver of mice prevents genetic- and diet-induced steatohepatitis by increasing TG hydrolase activity and FA oxidation and reduces SREBP1c mediated lipogenesis, inflammation, apoptosis and fibrosis. ${ }^{259,260}$.

Murine Ces $2 \mathrm{c}$ is a highly abundant TG, DG and MG hydrolase in liver and intestine $e^{258,261}$. Its expression is decreased in livers of mice with diet- or genetically induced obesity ${ }^{258,261}$. Loss of hepatic Ces2c in chow- or western-diet-fed mice causes hepatic steato$\operatorname{sis}^{258}$. Conversely, increasing hepatic Ces $2 c$ expression ameliorated obesity and hepatic steatosis, and improved glucose tolerance and insulin sensitivity ${ }^{258}$. Mechanistically, FAs released by Ces2c enter FA oxidation and concomitantly inhibit SREBP1 activity to decrease de novo lipogenesis in the liver ${ }^{258}$. Similarly, intestine-specific transgenic expression of Ces $2 \mathrm{c}$ in mice also promotes intestinal TG hydrolysis and FA oxidation, and ameliorates high-fat-diet-induced obesity and NAFLD ${ }^{262}$. Moreover, an increased re-esterification rate of MGs and DGs may contribute to the generation of large chylomicrons that undergo accelerated postprandial TG clearance ${ }^{262}$. Taken together, the physiological function of both human CES2 and murine Ces $2 c$ render this enzyme an attractive target for the treatment of metabolic liver disease.

Lipid-droplet-associated hydrolase. Lipid-droplet-associated hydrolase (LDAH) is another member of the $\alpha / \beta$-hydrolase superfamily with predicted lipase activity but unclear function. The putative enzyme is mainly expressed in BAT, WAT, liver, heart and macrophages of atherosclerotic lesions ${ }^{263}$. LDAH harbours a GXSXG lipase motif within an $\alpha / \beta$-hydrolase fold and a hydrophobic motif that anchors the protein to cytosolic $\mathrm{LDs}^{263-265}$. While LDAH's localization to LDs is undisputed in multiple cell models, enzymatic activity and biological function of the protein remain unknown. The LDAH ortholog in D. melanogaster (CG9186) facilitates lipid packaging and regulates LD clustering in cell and tissue cultures of salivary glands ${ }^{264,266}$. Unfortunately, only conflicting data exist on the physiological function of the enzyme in mammalian cells. Goo et al. ${ }^{263}$ demonstrated that overexpression of human or mouse LDAH in human embryonic kidney cells or RAW-macrophages elevates CE turnover and cholesterol efflux, while silencing of the enzyme causes CE accumulation. The same group also showed that LDAH promotes LD accumulation by affecting ATGL ubiquitinylation and degradation ${ }^{267}$. In other studies, however, LDAH overexpression did not affect $\mathrm{CE}$, TG and retinyl ester hydrolase activity, and LDAH ablation did not change CE turnover in bone-marrow-derived macrophages $^{265}$. Also, mice globally lacking LDAH exhibit normal CE, TG and whole-body energy metabolism, suggesting that LDAH either plays only a minor role in lipid metabolism or when absent is replaced by effective compensatory mechanisms ${ }^{265}$. Notably, genetic studies revealed that loss of LDAH may be associated with prostate cancer and sensorineural hearing loss ${ }^{268}$. Without a better functional characterization of this putative lipase, it is currently impossible to assess its role in lipid and energy homeostasis or cancer development.
DDH domain-containing protein 2. DDH domain-containing protein 2 (DDHD2, also named KIAA0725 or iPLA1 $\gamma$ ) belongs to the mammalian intracellular phospholipase A1 (iPLA1) family which consists of three paralogs-DDHD1, DDHD2 and SEC23IP. All members share a conserved GXSXG lipase motif and a DDHD domain named after a characteristic amino acid signature within the domain ${ }^{269,270}$. DDHD2 exhibits DG and TG hydrolase activity, and DDHD2 deficiency in mice causes TG accumulation in the brain $^{271-274}$. The human DDHD2 gene encodes a 711-amino-acid protein with a molecular weight of $81 \mathrm{kDa}$. The protein localizes to the cytosol, Golgi apparatus and $\mathrm{ER}^{274,275}$. In humans, loss-of-function mutations in DDHD2 lead to hereditary spastic paraplegia $^{276-278}$, a neurodegenerative disorder associated with lipid accumulation in the brain and characterized by spasticity in the lower limbs ${ }^{276}$. Putative DDHD2-dependent mechanisms that may underlie hereditary spastic paraplegia include (1) the accrual of LDs, which would hinder protein and/or lipid trafficking required for synapse assembly ${ }^{276}$, (2) reduced cardiolipin biosynthesis and increased ROS production in mitochondria, which would trigger apoptosis of motor neurons in the spinal $\operatorname{cord}^{279}$ and (3) altered mobilization of FAs from LDs, which would affect membrane phospholipid composition and neuronal function ${ }^{280}$. Additionally, short-hairpin-RNA-mediated DDHD2 knockdown was shown to impair phospholipid synthesis and sensory axon regeneration after sciatic nerve crush ${ }^{281}$, emphasizing a crucial role for lipolysis in neuron function. Moreover, genome-wide analyses identified DDHD2 as a candidate risk gene for other neurological diseases, including autism and schizophrenia ${ }^{282,283}$. Whether these diseases are directly linked to the enzymatic activity of DDHD2 is currently investigated.

Arylacetamide deacetylase. Arylacetamide deacetylase (AADAC) is a $45-\mathrm{kDa}$ esterase that harbours a typical GXSXG motif and exhibits considerable sequence homology to HSL in its presumed active site $^{284}$. AADAC localizes to the ER and is mainly expressed in liver and intestine with much lower expression in adrenal glands and pancreas $^{284,285}$. AADAC preferably hydrolyses cholesteryl acetate and DGs over $\mathrm{TGs}^{286,287}$. Its diurnal expression pattern is identical to hepatic VLDL secretion in mice and depends on transcriptional regulation by PPAR $\alpha\left(\right.$ ref. $\left.{ }^{285}\right)$. Overexpression of AADAC in human (HepG2) and rat (McA) hepatoma cells increases TG secretion and reduces TG accumulation, respectively, indicating that it might play a role in lipid mobilization for VLDL synthesis ${ }^{286,288}$. Another study has demonstrated that, although hepatic AADAC activity is decreased in humans with obesity, there was no association to the homeostasis model assessment (HOMA) index or with DG species, and knockdown of endogenous AADAC did not affect FA oxidation in primary human hepatocytes ${ }^{259}$. Accordingly, the role of AADAC in lipid metabolism in vivo is still elusive.

Exosome-mediated TG mobilization. Extracellular vesicles (EVs) represent a recently discovered mechanism for the utilization of TG stores. In contrast to lipolysis and lipophagy, EV-mediated TG utilization does not involve TG hydrolysis and subsequent FA distribution. Instead, LDs are directly released from cells within EVs. A familiar, unique subclass of EVs containing large amounts of TGs are milk fat globules. They originate from cuboidal epithelial cells of lactating mammary glands and are secreted into milk ducts ${ }^{289}$. Apart from the very distinct milk fat globules, EVs are generally secreted from almost all cell types and are found in interstitial fluid and many other body fluids. The term EV subsumes two major types of vesicles, which differ in size and origin: (1) exosomes, which are $30-150 \mathrm{~nm}$ in diameter and originate from intraluminal vesicles of the endosomal system and (2) microvesicles, which are 100- to $1,000-\mathrm{nm}$ structures blebbing off the plasma membrane ${ }^{290}$. After their release, EVs are internalized by other cells, enabling the horizontal transfer of cargo from donor to recipient cells. The nature of 

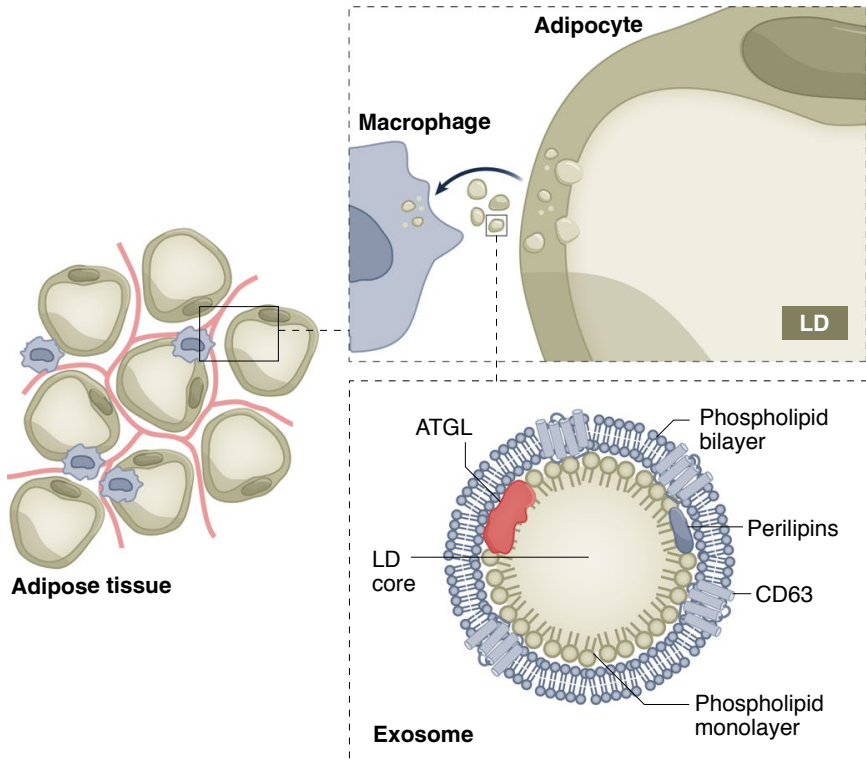

Fig. 5 | Exosome-mediated TG mobilization. TGs are shuttled from adipocytes to macrophages in adipose tissue via exosomes. Exosomes comprise a phospholipid bilayer and phospholipid monolayer engulfing the hydrophobic core of enclosed LDs and harbour exosomal marker proteins, such as CD63, and LD proteins, such as perilipins or ATGL.

their cargo is manifold and includes proteins, nucleic acids, various metabolites and even intact organelles ${ }^{290}$. EVs have thus been attributed diverse biological functions ranging from immunomodulation to tissue differentiation and cancer development ${ }^{291}$.

Importantly, Ferrante and colleagues reported that adipocyte-derived EVs are able to transport TGs to adipose-tissue-resident macrophages ${ }^{292}$. Similar to all EVs, TG-containing exosomes are enclosed by a phospholipid bilayer derived from the plasma membrane of EV-producing cells ${ }^{292}$. Additionally, a phospholipid monolayer engulfs the hydrophobic core of enclosed LDs ${ }^{292}$ (Fig. 5). Ex vivo experiments have demonstrated that mobilization of TGs via exosomes accounts for up to $2 \%$ of the cellular lipid release per day, independent of canonical FA mobilization by lipolysis. Adipocyte-derived exosomes are almost exclusively taken up by macrophages and may thus represent an alternative pathway for local intercellular lipid distribution in adipose tissue. Through this process, macrophages may adapt to their local adipose tissue environment, consistent with similar findings in other tissues ${ }^{292}$. Whether adipocyte-derived EVs can transport TG cargo to cells and tissues other than macrophages remains to be elucidated.

Sebocytes represent another cell type secreting large amounts of mostly neutral lipids including TGs. These lipids accumulate in LDs during sebocyte differentiation but in contrast to adipocytes, lipid mobilization occurs via sebocyte necrosis instead of lipolysis or exosome-mediated pathways ${ }^{293}$. Interestingly, Kanbayashi and colleagues $^{294}$ recently discovered an immune-metabolic signalling axis whereby thymic stromal lymphopoietin (TSLP) induces hypersecretion of sebum via $\mathrm{CD}^{+}$and $\mathrm{CD}^{+} \mathrm{T}$ cell activation. Sebum hypersecretion is associated with increased fat catabolism in adipose tissue and associated with adipose tissue loss in a TSLP transgenic mouse model.

\section{Therapeutic potential of lipolysis inhibition}

Considering the essential role of lipolytic enzymes in systemic and tissue-specific energy homeostasis, the inhibition of lipolysis may offer potential treatment opportunities for various metabolic, and possibly even infectious, diseases. Example target diseases are described below and in Box 1.

Type 2 diabetes. Type 2 diabetes is a serious public-health concern that impairs quality and expectancy of life. Obesity represents the major risk factor for type 2 diabetes ${ }^{295}$. It is well accepted that an increased FA flux from hypertrophic adipose tissue to insulin-sensitive tissues contributes to insulin resistance and glucose intolerance ${ }^{296}$. Accordingly, reduced FA mobilization from adipose tissue in mice with global or adipocyte-specific deletion of ATGL, HSL or LAL leads to significantly increased glucose tolerance and improved insulin sensitivity $24,27,185,297-299$. For HSL deficiency, the beneficial metabolic phenotype is present in old, but not young, mice, and may be due to a concomitant decline in ATGL activity, which strongly impairs FA mobilization from adipose stores in older animals ${ }^{40}$. Interestingly, HSL deficiency in humans leads to insulin resistance, arguing for considerable species-specific differences in HSL's role in controlling carbohydrate metabolism. Pharmacological inhibition of $\mathrm{ATGL}^{300}$ or $\mathrm{HSL}^{301}$ also improved glucose tolerance and insulin sensitivity in high-fat-diet-fed mice. A shift towards glucose utilization upon reduced FA availability from adipose tissue, reduced hepatic acetyl-CoA levels and pyruvate carboxylase activity and, consequently, reduced hepatic glucose production contributes to increased glucose tolerance in mice with adipocyte-specific ATGL deficiency ${ }^{302}$.

Hypoinsulinemia occurs in both ATGL- and HSL-deficient mice and likely contributes to the insulin-sensitive phenotype ${ }^{27,298,300,301}$. Insulin, secreted from pancreatic $\beta$-cells, regulates lipid versus carbohydrate utilization as fuel for energy. $\beta$-cell-intrinsic lipolysis generates various lipid intermediates with signalling potential like MGs, FA-CoAs and FAs that were shown to regulate glucose-stimulated insulin secretion (GSIS) ${ }^{303}$. Studies in global- and $\beta$-cell-specific ATGL and HSL-deficient mice revealed impaired GSIS of isolated pancreatic islets and hypoinsulinemia ${ }^{26,31,304-307}$. In contrast, inhibition of LAL in pancreatic $\beta$-cells indirectly potentiates GSIS by activating ATGL and $\mathrm{HSL}^{308}$. Several mechanisms have been proposed for impaired insulin secretion in ATGL-deficient $\beta$-cells, including (1) reduced availability of PPAR $\delta$ ligands resulting in mitochondrial dysfunction $^{31}$, (2) reduced generation of MGs that induce insulin exocytosis by binding to the vesicle priming protein Munc13-1 (refs. ${ }^{26,309}$ ) or (3) reduced palmitoylation and stability of SNARE protein syntaxin 1a (Stxla), which is crucial for insulin secretion ${ }^{305}$. Moreover, FAs liberated from adipose tissue promote insulin secretion after $\beta$-adrenergic stimulation ${ }^{310}$ and reduced or diminished adipocyte ATGL or HSL activity perturbs insulin secretion from $\beta$-cells $s^{27,298-300,311}$. Hence, specifically manipulating adipocyte lipolysis may represent a potential pharmacological approach to improve insulin sensitivity and glucose tolerance.

Fatty liver disease. NAFLD affects approximately $25 \%$ of the global population $^{312}$. In around $10 \%$ of all cases, NAFLD progresses from relatively benign hepatic steatosis to nonalcoholic steatohepatitis (NASH), which can further evolve to liver cirrhosis and hepatocellular carcinoma (HCC) ${ }^{313}$. Obesity-associated NAFLD results from either increased de novo TG synthesis in the liver or increased flux of FAs from adipose tissue to the liver, or both ${ }^{314}$. Accordingly, reduced FA mobilization from adipocytes ameliorates hepatic steatosis, inflammation and fibrosis in high-fat-diet-fed mice that have adipocyte-specific ATGL deficiency or CGI-58 deficiency or that have been treated with atglistatin ${ }^{298,300,315}$. Somewhat counterintuitively, overexpression of ATGL in adipocytes also improves hepatic steatosis in a transgenic mouse model ${ }^{316}$. However, evidence shows that enhanced FA oxidation in adipose tissues of adipocyte-specific ATGL transgenic mice reduces FA flux to the liver, resulting in decreased hepatic fat storage. 


\section{Box 1 | Pathogen-mediated lipolytic reprogramming and its inhibition}

Viruses are obligate intracellular pathogens that hijack host cells and create an intracellular metabolic niche to facilitate efficient replication and virion production. Striking examples of such hostile takeovers include positive-stranded RNA viruses that rewire lipid metabolism to form membrane platforms, so called replication compartments (RCs) providing a structural framework for RNA synthesis ${ }^{339-341}$. These RCs additionally enable local accrual of viral macromolecules and hinder host defence mechanisms. Flaviviruses including dengue virus, West Nile virus and hepatitis $\mathrm{C}$ virus (HCV), as well as severe acute respiratory syndrome coronavirus (SARS-CoV) ${ }^{342}$, exploit ER membranes for RC formation. Picornaviruses, a large family of positive-stranded RNA viruses, stimulate phospholipid-especially phosphatidylcholine-biosynthesis to form $\mathrm{RCs}^{343}$. Accordingly, virus-infected cells upregulate FA uptake and CoA activation ${ }^{34}$. Notably, however, exogenous FAs do not directly enter phospholipid synthesis but are first esterified to TGs by DGAT1 and deposited in $\mathrm{LDs}^{345}$. On demand, activation of lipolysis promotes FA release and subsequent RC-membrane synthesis. During infection by enteroviruses, including rhinovirus, inhibition of DGAT1, ATGL or HSL largely reduces viral replication $^{341}$. To access cellular lipid stores, viruses use newly formed membrane contact sites between LDs and RCs. A direct interaction of viral proteins with ATGL and HSL at these contact sites may promote FA channelling towards RC synthesis ${ }^{341}$.

Besides providing FAs for RC formation, LDs also serve as platforms for HCV and dengue virus-particle synthesis ${ }^{339,346}$, and inhibition of LD formation decreases dengue virus and HCV replication ${ }^{339}$. For both viruses, particle morphogenesis depends on the localization of the basic core protein to LDs, from which it is recruited for virus particle formation ${ }^{347}$. The interface between LDs and ER may serve as HCV assembly platforms ${ }^{341}$. Once bound to LDs, HCV core protein inhibits ATGL-mediated lipolysis ${ }^{348}$ to increase LD volume and number. This process likely contributes to the hepatic steatosis commonly observed in people infected with $\mathrm{HCV}^{349}$. Similarly, accumulation of LDs was also observed in infected African green monkey kidney epithelial cells and in lungs of people infected with SARS-CoV-2, suggesting that SARS-CoV-2 pathogenesis also involves lipid metabolism ${ }^{350}$.

Lipolysis of LD-associated TGs furthermore provides energy substrates for ATP production that are required for viral replication and virion formation. In some cases, such as upon infection with the lymphocytic choriomeningitis (LCM) virus, activation of neutral lipolysis via ATGL and HSL is so pronounced that it contributes to the drastic reduction in mass of adipose tissue in infected mice ${ }^{351}$. Other viruses, such as dengue virus $^{352}$, influenza $(\mathrm{H} 3 \mathrm{~N} 2)$ virus $^{353}$ and porcine reproductive and respiratory syndrome virus ${ }^{354}$, activate lipophagy and acid lipolysis to mobilize FAs from LDs. FAs are subsequently oxidized in mitochondria to fuel viral replication. Similarly, poliovirus ${ }^{355}$, $\mathrm{HCV}^{356}$ and coxsackievirus B3 (ref. ${ }^{357}$ ) replication also requires cellular autophagy and lysosomal lipid degradation. Thus, virus infections inhibit or activate lipolysis depending on whether the virus utilizes LDs as an assembly and replication platform or as a source of FAs as an energy substrate, respectively.

Following virus assembly, viral particles often hijack host cells' transport systems to leave infected cells by budding or exocytosis. HCV exploits the VLDL synthesis pathway to exit hepatocytes as lipo-viro-particles ${ }^{347}$. Knockdown of arylacetamide deacetylase (AADAC), a putative lipase involved in VLDL synthesis, largely decreases virus production ${ }^{358}$. Moreover, $\mathrm{HCV}$ production depends on hepatic CGI-58 (ref. ${ }^{359}$ ). Loss-of-function mutations in CGI58 , which are associated with NLSDI, diminish HCV production, indicating that the prolipolytic function of CGI-58, but not of ATGL, is required for HCV formation. The contradiction that the HCV life cycle depends on inactive ATGL but active CGI-58 may be resolved by the identification of an ATGL-independent role of CGI-58 in VLDL synthesis ${ }^{360}$.

Finally, adipose tissue is also a refuge for several pathogenic parasites, including Trypanosoma cruzi ${ }^{361}$, Trypanosoma brucei ${ }^{362}$, Coxiella burnetiid ${ }^{363}$, Rickettsia prowazekii ${ }^{364}$ and Mycobacterium tuberculosis ${ }^{365}$. T. cruzi causes Chagas disease and invades adipocytes, where it resides in close proximity to LDs, ensuring that the parasite has a continuous supply of FAs ${ }^{366}$. Adipose tissue represents a major reservoir for T. brucei, which adapts to the lipid-rich environment by increased ATGL-mediated lipolysis and FA oxidation to satisfy their energy requirements ${ }^{362}$. This catabolic switch towards fat catabolism would also explain the weight loss in people and cattle with sleeping sickness caused by this parasite ${ }^{367,368}$. Studies in Listeria monocytogenes-infected mice demonstrated a link between fasting and increased survival, and forced feeding of infected mice with a glucose-containing diet was lethal ${ }^{369}$. Apparently, lipolysis-associated metabolites like ketone bodies are essential for surviving $L$. monocytogenes infections. Anorexia and even cachexia accompany most infections and may be seen as host defence mechanisms to mimic fasting and activate adipose-tissue FA mobilization for ketogenesis in the liver to improve immune function and increase the chance of survival.
Numerous GWAS and candidate-gene studies have demonstrated that the PNPLA3-I148M variant represents a strong genetic risk factor for steatohepatitis, fibrosis and $\mathrm{HCC}^{220}$. ASO-mediated silencing of PNPLA3 improved NAFLD and fibrosis in a mutant knock-in mouse model harbouring the PNPLA3-I148M muta$\operatorname{tion}^{317}$. Therapeutic interventions that lower PNPLA3-I148M protein levels, such as SREBP1C inhibitors or antisense/silencing approaches, are likely to be beneficial in ameliorating NAFLD ${ }^{318}$. Moreover, PNPLA3-I148M sequesters CGI-58 from its interaction with ATGL and impairs its hydrolytic activity for LD-associated $\mathrm{TGs}^{139}$. Disrupting the interaction of PNPLA3 with CGI-58 by small molecules, as already reported for the CGI-58/perilipin-1 interaction $^{134}$, may offer a potent therapeutic strategy to restore hepatic TG hydrolysis and prevent NAFLD in carriers of the I148M variant ${ }^{134}$. This therapeutic concept is corroborated by the finding that diet-induced hepatic steatosis is prevented by adenovirus-mediated overexpression of ATGL in murine livers ${ }^{319}$.
Heart failure. Chronic heart failure (HF) is a common disease resulting from any structural or functional impairment of ventricular filling or ejection of blood ${ }^{320}$. HF represents a leading cause of death and can basically be subdivided into two distinct groups: HF with preserved ejection fraction (HFpEF) and HF with restricted ejection fraction (HFrEF) ${ }^{320}$. In developed countries, the prevalence of $\mathrm{HF}$ in the adult population is about $1-2 \%$, and the 5-year mortality rate reaches up to $75 \%$ of people with the condition ${ }^{321}$. HFpEF, which comprises around $50 \%$ of HF cases, is often associated with metabolic disorders such as obesity, diabetes and hypertension ${ }^{321}$. The healthy heart exhibits high flexibility to use FA, glucose and ketone bodies as energy substrates ${ }^{322}$. During cardiac failure, metabolic flexibility is reduced, and the heart increasingly uses glucose as energy fuel ${ }^{322}$. However, a chronic activation of the sympathetic nervous system and an increase in natriuretic peptides augments adipose FA mobilization, which competes with glucose utilization and aggravates oxidative stress during $\mathrm{HF}^{323-325}$. Accordingly, 
adipocyte-specific ATGL deficiency or atglistatin treatment protected mice from pressure-induced cardiac hypertrophy and cardiac fibrosis $^{326,327}$. Similarly, ATGL inhibition promoted a cardioprotective effect in a mouse model of catecholamine-induced cardiac damage $^{328}$. It has been suggested that inhibition of adipocyte ATGL activity improves cardiac energy metabolism by further shifting substrate utilization from FAs towards glucose and by changing the cardiac membrane lipid composition ${ }^{329}$. Future studies will address the potential of ATGL inhibition in 'metabolic' models of HFpEF, such as the hypertensive mouse fed a high-fat diet ${ }^{330}$. Considering the current lack of effective therapeutics, the pharmacological inhibition of ATGL, and possibly other lipases in adipose tissue, may represent a promising approach to treat HFpEF. Importantly, however, the inhibition of lipolysis must be restricted to adipose tissue because concomitant suppression of lipolysis in cardiac myocytes, hepatocytes and other non-adipose tissues may result in steatosis and organ dysfunction, as present in people with global ATGL ${ }^{21,23}$ or CGI-58 deficiency ${ }^{136}$.

Cachexia. Cachexia is a severe wasting disorder accompanying the late stage of various diseases such as rheumatoid arthritis, chronic obstructive pulmonary disease, burn-induced trauma or cancer $^{331}$. The occurrence of cachexia in any of these maladies drastically decreases treatment options and chances of survival. Cachexia is a hypermetabolic disorder characterized by systemic inflammation and an unintended loss of body weight due to a reduction in adipose tissue and skeletal muscle mass that cannot be reversed by increased nutritional intake ${ }^{331,332}$. To date, the multifactorial mechanisms causing cachexia are yet insufficiently understood and effective treatments are not available. Adipose tissue loss often precedes muscle loss in cachexia, and some studies have provided evidence that halting fat depletion also preserves muscle mass ${ }^{333,334}$. Hence, recent studies engage a more 'adipocentric' view of cachexia development ${ }^{335}$. Mechanistically, adipose tissue undergoes a switch towards catabolism that is initiated by proinflammatory cytokines and amplified by $\beta$-adrenergic signals ${ }^{336,337}$. This catabolic reprogramming elevates lipolysis and futile cycling, but reduces lipogenesis and fat accumulation, leading to adipose tissue atrophy ${ }^{332,335}$. Reducing lipolysis by pharmacological or genetic inhibition of $\mathrm{ATGL}^{333,338}$ or by targeting the erroneously prolipolytic signals, like the $\beta 3$-adrenergic signal ${ }^{336}$ or the AMPK-CIDEA axis ${ }^{130}$, prevented adipose-tissue loss in murine cachexia models of burn-induced trauma or cancer. Interestingly, ATGL blockade not only reduced lipolysis but also prevented browning of WAT and fatty-liver development post burn injury ${ }^{338}$ and muscle atrophy in some mouse models of cancer cachexia ${ }^{333}$. The mechanisms underlying the tumour-adipose tissue-muscle crosstalk in cachexia and the question of whether lipolysis inhibition affects cachexia in humans await future clarification.

\section{Conclusion}

Discoveries in the past two decades have turned intracellular TG catabolism from a relatively simple, single-enzyme reaction by HSL to a complex, highly regulated pathway that affects energy homeostasis on numerous levels. While canonical lipolysis of intracellular lipid stores is by now relatively well-characterized, the contribution of noncanonical enzymes and the role of lysosomal acid lipolysis for cytoplasmic LD degradation require comprehensive characterization. In many cases, the enzymatic function of these proteins as well as their placement in lipid metabolism and physiology remain unclear, despite compelling evidence for their relevance in disease development. A good example for such dreadful lack of knowledge relates to the crucial yet unsettled function of PNPLA3 in lipid metabolism and liver disease. Another exciting topic of future research will address the therapeutic potential of lipolytic enzymes to treat metabolic disorders. Examples include inhibition of ATGL (and possibly HSL) to treat or prevent type 2 diabetes, fatty liver disease, lethal heart failure or cachexia. While preclinical experiments in mice are promising, their potential in humans remains completely unknown. Similarly, it is of utmost interest to find out whether inhibition of PNPLA3 prevents NASH, liver cirrhosis and liver cancer in humans. Future focus on these topics is likely to open preventative and therapeutic opportunities for the treatment of metabolic diseases.

Received: 4 August 2021; Accepted: 15 October 2021;

Published online: 19 November 2021

\section{References}

1. Unger, R. H. \& Scherer, P. E. Gluttony, sloth and the metabolic syndrome: a roadmap to lipotoxicity. Trends Endocrinol. Metab. 21, 345-352 (2010).

2. Walther, T. C., Chung, J. \& Farese, R. V. Lipid droplet biogenesis. Annu. Rev. Cell Dev. Biol. 33, 491-510 (2017).

3. Whitehead, R. H. A note on the absorption of fat. Am. J. Physiol. Content 24, 294-296 (1909).

4. Vaughan, M., Berger, J. E. \& Steinberg, D. Hormone-sensitive lipase and monoglyceride lipase activities in adipose tissue. J. Biol. Chem. 239, 401-409 (1964).

5. Osuga, J.-I. et al. Targeted disruption of hormone-sensitive lipase results in male sterility and adipocyte hypertrophy, but not in obesity. Proc. Natl Acad. Sci. USA 97, 787-792 (2000).

6. Haemmerle, G. et al. Hormone-sensitive lipase deficiency in mice causes diglyceride accumulation in adipose tissue, muscle, and testis. J. Biol. Chem. 277, 4806-4815 (2002)

7. Zimmermann, R. et al. Fat mobilization in adipose tissue is promoted by adipose triglyceride lipase. Science 306, 1383-1386 (2004).

8. Jenkins, C. M. et al. Identification, cloning, expression, and purification of three novel human calcium- independent phospholipase A2 family members possessing triacylglycerol lipase and acylglycerol transacylase activities. J. Biol. Chem. 279, 48968-48975 (2004).

9. Lass, A. et al. Adipose triglyceride lipase-mediated lipolysis of cellular fat stores is activated by CGI-58 and defective in Chanarin-Dorfman syndrome. Cell Metab. 3, 309-319 (2006).

10. Kienesberger, P. C., Oberer, M., Lass, A. \& Zechner, R. Mammalian patatin domain containing proteins: a family with diverse lipolytic activities involved in multiple biological functions. J. Lipid Res. 50, 63-68 (2009).

11. Schweiger, M. et al. The C-terminal region of human adipose triglyceride lipase affects enzyme activity and lipid droplet binding. J. Biol. Chem. 283, 17211-17220 (2008)

12. Ahmadian, M. et al. Desnutrin/ATGL is regulated by AMPK and is required for a brown adipose phenotype. Cell Metab. 13, 739-748 (2011).

13. Pagnon, J. et al. Identification and functional characterization of protein kinase A phosphorylation sites in the major lipolytic protein, adipose triglyceride lipase. Endocrinology 153, 4278-4289 (2012).

14. Zhang, X. et al. An epistatic interaction between Pnpla2 and Lipe reveals new pathways of adipose tissue lipolysis. Cells 8, 395 (2019).

15. Brejchova, K. et al. Distinct roles of adipose triglyceride lipase and hormone-sensitive lipase in the catabolism of triacylglycerol estolides. Proc. Natl Acad. Sci. USA 118, e2020999118 (2021).

16. Ohno, Y., Kamiyama, N., Nakamichi, S. \& Kihara, A. PNPLA1 is a transacylase essential for the generation of the skin barrier lipid $\omega$-O-acylceramide. Nat. Commun. 8, 14610 (2017).

17. Soni, K. G. et al. Coatomer-dependent protein delivery to lipid droplets. J. Cell Sci. 122, 1834-1841 (2009).

18. Ellong, E. N. et al. Interaction between the triglyceride lipase ATGL and the Arf1 activator GBF1. PLoS ONE 6, e21889 (2011).

19. Wang, T. et al. OSBPL2 is required for the binding of COPB1 to ATGL and the regulation of lipid droplet lipolysis. iScience 23, 101252 (2020).

20. Cai, M. et al. FAM134B promotes adipogenesis by increasing vesicular activity in porcine and 3T3-L1 adipocytes. Biol. Chem. 400, 523-532 (2019).

21. Fischer, J. et al. The gene encoding adipose triglyceride lipase (PNPLA2) is mutated in neutral lipid storage disease with myopathy. Nat. Genet. 39, 28-30 (2007).

22. Missaglia, S., Coleman, R., Mordente, A. \& Tavian, D. Neutral lipid storage diseases as cellular model to study lipid droplet function. Cells $\mathbf{8}$, 187 (2019).

23. Hirano, K.-I., Ikeda, Y., Zaima, N., Sakata, Y. \& Matsumiya, G. Triglyceride deposit cardiomyovasculopathy. N. Engl. J. Med. 359, 2396-2398 (2008)

24. Haemmerle, G. et al. Defective lipolysis and altered energy metabolism in mice lacking adipose triglyceride lipase. Science 312, 734-737 (2006). 
25. Haemmerle, G. et al. ATGL-mediated fat catabolism regulates cardiac mitochondrial function via PPAR- $\alpha$ and PGC-1. Nat. Med. 17, 1076-1085 (2011).

26. Attané, C. et al. A beta cell ATGL-lipolysis/adipose tissue axis controls energy homeostasis and body weight via insulin secretion in mice. Diabetologia 59, 2654-2663 (2016).

27. Heine, M. et al. Lipolysis triggers a systemic insulin response essential for efficient energy replenishment of activated brown adipose tissue in mice. Cell Metab. 28, 644-655.e4 (2018).

28. Ong, K. T., Mashek, M. T., Bu, S. Y., Greenberg, A. S. \& Mashek, D. G. Adipose triglyceride lipase is a major hepatic lipase that regulates triacylglycerol turnover and fatty acid signaling and partitioning. Hepatology 53, 116-126 (2011)

29. Schreiber, R. et al. Hypophagia and metabolic adaptations in mice with defective ATGL-mediated lipolysis cause resistance to HFD-induced obesity. Proc. Natl Acad. Sci. USA 112, 13850-13855 (2015).

30. Mottillo, E. P., Bloch, A. E., Leff, T. \& Granneman, J. G. Lipolytic products activate peroxisome proliferator-activated receptor (PPAR) $\alpha$ and $\delta$ in brown adipocytes to match fatty acid oxidation with supply. J. Biol. Chem. 287, 25038-25048 (2012).

31. Tang, T. et al. Desnutrin/ATGL activates PPARס to promote mitochondrial function for insulin secretion in islet $\beta$ cells. Cell Metab. 18, 883-895 (2013).

32. Khan, S. A. et al. ATGL-catalyzed lipolysis regulates SIRT1 to control PGC-1 $\alpha /$ PPAR- $\alpha$ signaling. Diabetes 64, 418-426 (2015).

33. Najt, C. P. et al. Lipid droplet-derived monounsaturated fatty acids traffic via PLIN5 to allosterically activate SIRT1. Mol. Cell 77, 810-824.e8 (2020)

34. Hofer, P. et al. Fatty acid-binding proteins interact with comparative gene identification-58 linking lipolysis with lipid ligand shuttling. J. Biol. Chem. 290, 18438-18453 (2015).

35. Recazens, E., Mouisel, E. \& Langin, D. Hormone-sensitive lipase: sixty years later. Prog. Lipid Res. 82, 101084 (2021).

36. Albert, J. S. et al. Null mutation in hormone-sensitive lipase gene and risk of type 2 diabetes. N. Engl. J. Med. 370, 2307-2315 (2014).

37. Farhan, S. M. K. et al. A novel LIPE nonsense mutation found using exome sequencing in siblings with late-onset familial partial lipodystrophy. Can. J. Cardiol. 30, 1649-1654 (2014).

38. Morigny, P. et al. Interaction between hormone-sensitive lipase and ChREBP in fat cells controls insulin sensitivity. Nat. Metab. 1, 133-146 (2019).

39. Zimmermann, R. et al. Decreased fatty acid esterification compensates for the reduced lipolytic activity in hormone-sensitive lipase-deficient white adipose tissue. J. Lipid Res. 44, 2089-2099 (2003).

40. Pajed, L. et al. Advanced lipodystrophy reverses fatty liver in mice lacking adipocyte hormone-sensitive lipase. Commun. Biol. 4, 323 (2021).

41. Hermo, L. et al. Alterations in the testis of hormone sensitive lipase-deficient mice is associated with decreased sperm counts, sperm motility, and fertility. Mol. Reprod. Dev. 75, 565-577 (2008).

42. Tornqvist, H. \& Belfrage, P. Purification and some properties of a monoacylglycerol-hydrolyzing enzyme of rat adipose tissue. J. Biol. Chem. 251, 813-819 (1976)

43. Karlsson, M., Contreras, J. A., Hellman, U., Tornqvist, H. \& Holm, C. cDNA cloning, tissue distribution, and identification of the catalytic triad of monoglyceride lipase. Evolutionary relationship to esterases, lysophospholipases, and haloperoxidases. J. Biol. Chem. 272, 27218-27223 (1997).

44. Savinainen, J. R. et al. Robust hydrolysis of prostaglandin glycerol esters by human monoacylglycerol lipase (MAGL). Mol. Pharmacol. 86, 522-535 (2014).

45. Heier, C. et al. Monoacylglycerol lipases act as evolutionarily conserved regulators of non-oxidative ethanol metabolism. J. Biol. Chem. 291 , 11865-11875 (2016).

46. Grabner, G. F., Zimmermann, R., Schicho, R. \& Taschler, U. Monoglyceride lipase as a drug target: at the crossroads of arachidonic acid metabolism and endocannabinoid signaling. Pharmacol. Ther. 175, 35-46 (2017).

47. Chon, S.-H., Zhou, Y. X., Dixon, J. L. \& Storch, J. Intestinal monoacylglycerol metabolism: developmental and nutritional regulation of monoacylglycerol lipase and monoacylglycerol acyltransferase. J. Biol. Chem. 282, 33346-33357 (2007).

48. Rakhshandehroo, M. et al. Comprehensive analysis of PPAR $\alpha$-dependent regulation of hepatic lipid metabolism by expression profiling. PPAR Res. 2007, 26839 (2007)

49. Rajasekaran, D. et al. Staphylococcal nuclease and tudor domain containing 1 (SND1 protein) promotes hepatocarcinogenesis by inhibiting monoglyceride lipase (MGLL). J. Biol. Chem. 291, 10736-10746 (2016).

50. Thomas, G. et al. The serine hydrolase ABHD6 is a critical regulator of the metabolic syndrome. Cell Rep. 5, 508-520 (2013).

51. Pribasnig, M. A. et al. $\alpha / \beta$ hydrolase domain-containing 6 (ABHD6) degrades the late endosomal/lysosomal lipid bis(monoacylglycero) phosphate. J. Biol. Chem. 290, 29869-29881 (2015).
52. Grabner, G. F. et al. Metabolic disease and ABHD6 alter the circulating bis(monoacylglycerol)phosphate profile in mice and humans. J. Lipid Res. 60, 1020-1031 (2019).

53. Poursharifi, P., Madiraju, S. R. M. \& Prentki, M. Monoacylglycerol signalling and ABHD6 in health and disease. Diabetes, Obes. Metab. 19, 76-89 (2017).

54. Tang, Z. et al. Enhanced monoacylglycerol lipolysis by ABHD6 promotes NSCLC pathogenesis. EBioMedicine 53, 102696 (2020).

55. Grüner, B. M. et al. An in vivo multiplexed small-molecule screening platform. Nat. Methods 13, 883-889 (2016).

56. Tardelli, M. et al. Lack of monoacylglycerol lipase prevents hepatic steatosis by favoring lipid storage in adipose tissue and intestinal malabsorption. J. Lipid Res. 60, 1284-1292 (2019).

57. Douglass, J. D. et al. Global deletion of monoacylglycerol lipase in mice delays lipid absorption and alters energy homeostasis and diet-induced obesity. J. Lipid Res. 56, 1153-1171 (2015).

58. Taschler, U. et al. Monoglyceride lipase deficiency in mice impairs lipolysis and attenuates diet-induced insulin resistance. J. Biol. Chem. 286, 17467-17477 (2011)

59. Chanda, P. K. et al. Monoacylglycerol lipase activity is a critical modulator of the tone and integrity of the endocannabinoid system. Mol. Pharmacol. 78, 996-1003 (2010)

60. Schlosburg, J. E. et al. Chronic monoacylglycerol lipase blockade causes functional antagonism of the endocannabinoid system. Nat. Neurosci. 13, 1113-1119 (2010).

61. Nomura, D. K. et al. Endocannabinoid hydrolysis generates brain prostaglandins that promote neuroinflammation. Science 334, 809-813 (2011).

62. Grabner, G. F. et al. Deletion of monoglyceride lipase in astrocytes attenuates lipopolysaccharide-induced neuroinflammation. J. Biol. Chem. 291, 913-923 (2016)

63. Nomura, D. K. et al. Monoacylglycerol lipase regulates a fatty acid network that promotes cancer pathogenesis. Cell 140, 49-61 (2010).

64. Zhang, J. et al. Monoacylglycerol lipase: a novel potential therapeutic target and prognostic indicator for hepatocellular carcinoma. Sci. Rep. 6, 35784 (2016).

65. Deng, H. \& Li, W. Therapeutic potential of targeting $\alpha / \beta$-Hydrolase domain-containing 6 (ABHD6). Eur. J. Med. Chem. 198, 112353 (2020).

66. Frühbeck, G., Méndez-Giménez, L., Fernández-Formoso, J.-A., Fernández, S. \& Rodríguez, A. Regulation of adipocyte lipolysis. Nutr. Res. Rev. 27, 63-93 (2014).

67. Yogosawa, S., Mizutani, S., Ogawa, Y. \& Izumi, T. Activin receptor-like kinase 7 suppresses lipolysis to accumulate fat in obesity through downregulation of peroxisome proliferator-activated receptor $\gamma$ and C/EBP $\alpha$. Diabetes 62, 115-123 (2013).

68. Roy, D. et al. Coordinated transcriptional control of adipocyte triglyceride lipase (Atgl) by transcription factors $\mathrm{Sp} 1$ and peroxisome proliferatoractivated receptor $\gamma(\operatorname{PPAR} \gamma)$ during adipocyte differentiation. J. Biol. Chem. 292, 14827-14835 (2017).

69. Kim, J. Y., Tillison, K., Lee, J.-H., Rearick, D. A. \& Smas, C. M. The adipose tissue triglyceride lipase ATGL/PNPLA2 is downregulated by insulin and TNF-alpha in 3T3-L1 adipocytes and is a target for transactivation by PPAR $\gamma$. Am. J. Physiol. Endocrinol. Metab. 291, E115-E127 (2006).

70. Stenson, B. M. et al. Liver X receptor (LXR) regulates human adipocyte lipolysis. J. Biol. Chem. 286, 370-379 (2011).

71. Kulcenty, K., Holysz, M. \& Trzeciak, W. H. SF-1 (NR5A1) expression is stimulated by the PKA pathway and is essential for the PKA-induced activation of LIPE expression in Y-1 cells. Mol. Cell. Biochem. 408, 139-145 (2015).

72. Gambo, Y., Matsumura, M. \& Fujimori, K. Triiodothyronine enhances accumulation of intracellular lipids in adipocytes through thyroid hormone receptor $\alpha$ via direct and indirect mechanisms. Mol. Cell. Endocrinol. 431, 1-11 (2016).

73. Fujimoto, Y. et al. TFE3 controls lipid metabolism in adipose tissue of male mice by suppressing lipolysis and thermogenesis. Endocrinology 154, 3577-3588 (2013)

74. Czajkowski, M. T., Holysz, M. \& Trzeciak, W. H. Induction of hormone-sensitive lipase/cholesteryl esterase gene expression by C/EBP $\alpha$ independently of the PKA pathway in the adrenocortical Y-1 cells. Steroids 104, 118-121 (2015)

75. Kaltenecker, D. et al. Adipocyte STAT5 deficiency promotes adiposity and impairs lipid mobilisation in mice. Diabetologia 60, 296-305 (2017).

76. Kaltenecker, D. et al. STAT5 is required for lipid breakdown and beta-adrenergic responsiveness of brown adipose tissue. Mol. Metab. 40, 101026 (2020).

77. Shi, S. Y. et al. Adipocyte-specific deficiency of Janus kinase (JAK) 2 in mice impairs lipolysis and increases body weight, and leads to insulin resistance with ageing. Diabetologia 57, 1016-1026 (2014). 
78. Hong, S. et al. Phosphorylation of beta-3 adrenergic receptor at serine 247 by ERK MAP kinase drives lipolysis in obese adipocytes. Mol. Metab. 12, 25-38 (2018).

79. Greenberg, A. S. et al. Stimulation of lipolysis and hormone-sensitive lipase via the extracellular signal-regulated kinase pathway. J. Biol. Chem. 276, 45456-45461 (2001).

80. Hjelholt, A. J. et al. Temporal patterns of lipolytic regulators in adipose tissue after acute growth hormone exposure in human subjects: A randomized controlled crossover trial. Mol. Metab. 29, 65-75 (2019).

81. Kopchick, J. J., Berryman, D. E., Puri, V., Lee, K. Y. \& Jorgensen, J. O. L. The effects of growth hormone on adipose tissue: old observations, new mechanisms. Nat. Rev. Endocrinol. 16, 135-146 (2020).

82. El-Merahbi, R. et al. The adrenergic-induced ERK3 pathway drives lipolysis and suppresses energy dissipation. Genes Dev. 34, 495-510 (2020).

83. Magnusson, B., Svensson, P. A., Carlsson, L. M. S. \& Sjöholm, K. Activin B inhibits lipolysis in 3T3-L1 adipocytes. Biochem. Biophys. Res. Commun. 395, 373-376 (2010)

84. $\mathrm{Bu}$, Y. et al. Insulin regulates lipolysis and fat mass by upregulating growth/ differentiation factor 3 in adipose tissue macrophages. Diabetes 67, 1761-1772 (2018).

85. Zhu, H. J. et al. The effect of myostatin on proliferation and lipid accumulation in 3T3-L1 preadipocytes. J. Mol. Endocrinol. $\mathbf{5 4}$ 217-226 (2015).

86. Modica, S. et al. Bmp4 promotes a brown to white-like adipocyte shift. Cell Rep. 16, 2243-2258 (2016).

87. Boon, M. R. et al. BMP7 activates brown adipose tissue and reduces diet-induced obesity only at subthermoneutrality. PLOS ONE 8, e74083 (2013).

88. Guo, T. et al. Adipocyte ALK7 links nutrient overload to catecholamine resistance in obesity. Elife 3, e03245 (2014)

89. Li, F., Yang, H., Duan, Y. \& Yin, Y. Myostatin regulates preadipocyte differentiation and lipid metabolism of adipocyte via ERK1/2. Cell Biol. Int. 35, 1141-1146 (2011).

90. Lee, S.-J. Targeting the myostatin signaling pathway to treat muscle loss and metabolic dysfunction. J. Clin. Invest. 131, e148372 (2021).

91. Langin, D. \& Arner, P. Importance of TNF $\alpha$ and neutral lipases in human adipose tissue lipolysis. Trends Endocrinol. Metab. 17, 314-320 (2006)

92. Li, Y. et al. A global perspective on FOXO1 in lipid metabolism and lipid-related diseases. Prog. Lipid Res. 66, 42-49 (2017).

93. Chakrabarti, P. \& Kandror, K. V. FoxO1 controls insulin-dependent adipose triglyceride lipase (ATGL) expression and lipolysis in adipocytes. J. Biol. Chem. 284, 13296-13300 (2009).

94. Barthel, A., Schmoll, D. \& Unterman, T. G. FoxO proteins in insulin action and metabolism. Trends Endocrinol. Metab. 16, 183-189 (2005).

95. Ow, J. R. et al. Remodeling of whole-body lipid metabolism and a diabetic-like phenotype caused by loss of CDK1 and hepatocyte division. eLife 9, e63835 (2020).

96. Saline, M. et al. AMPK and AKT protein kinases hierarchically phosphorylate the N-terminus of the FOXO1 transcription factor, modulating interactions with 14-3-3 proteins. J. Biol. Chem. 294, 13106-13116 (2019).

97. van der Heide, L. P. \& Smidt, M. P. Regulation of FoxO activity by CBP/ p300-mediated acetylation. Trends Biochem. Sci. 30, 81-86 (2005).

98. Chakrabarti, P. et al. SIRT1 controls lipolysis in adipocytes via FOXO1-mediated expression of ATGL. J. Lipid Res. 52, 1693-1701 (2011)

99. Jung, S. M. et al. Non-canonical mTORC2 signaling regulates brown adipocyte lipid catabolism through SIRT6-FoxO1. Mol. Cell 75, 807-822.e8 (2019)

100. Sun, C. et al. Adipose SNAIL1 regulates lipolysis and lipid partitioning by suppressing adipose triacylglycerol lipase expression. Cell Rep. 17, 2015-2027 (2016).

101. Chakrabarti, P., English, T., Shi, J., Smas, C. M. \& Kandror, K. V. Mammalian target of rapamycin complex 1 suppresses lipolysis, stimulates lipogenesis, and promotes fat storage. Diabetes 59, 775-781 (2010).

102. Paolella, L. M. et al. mTORC1 restrains adipocyte lipolysis to prevent systemic hyperlipidemia. Mol. Metab. 32, 136-147 (2020).

103. Zhang, X. et al. Sustained activation of autophagy suppresses adipocyte maturation via a lipolysis-dependent mechanism. Autophagy 16, 1668-1682 (2020).

104. Chakrabarti, P. et al. Insulin inhibits lipolysis in adipocytes via the evolutionarily conserved mTORC1-Egr1-ATGL-mediated pathway. Mol. Cell. Biol. 33, 3659-3666 (2013).

105. Saxton, R. A. \& Sabatini, D. M. mTOR signaling in growth, metabolism, and disease. Cell 168, 960-976 (2017).

106. Kumar, A. et al. Fat cell-specific ablation of rictor in mice impairs insulin-regulated fat cell and whole-body glucose and lipid metabolism. Diabetes 59, 1397-1406 (2010).

107. Caron, A., Richard, D. \& Laplante, M. The roles of mTOR complexes in lipid metabolism. Annu. Rev. Nutr. 35, 321-348 (2015).
108. Steinberg, D. \& Huttunen, J. K. The role of cyclic AMP in activation of hormone-sensitive lipase of adipose tissue. Adv. Cycl. Nucleotide Res. 1, 47-62 (1972).

109. Sveidahl Johansen, O. et al. Lipolysis drives expression of the constitutively active receptor GPR3 to induce adipose thermogenesis. Cell 184, 3502-3518.e33 (2021)

110. Kimmel, A. R. \& Sztalryd, C. The perilipins: major cytosolic lipid droplet-associated proteins and their roles in cellular lipid storage, mobilization, and systemic homeostasis. Annu. Rev. Nutr. 36, 471-509 (2016).

111. Carper, D. et al. Atrial natriuretic peptide orchestrates a coordinated physiological response to fuel non-shivering thermogenesis. Cell Rep. 32, 108075 (2020)

112. Yu, L., Li, Y., Grisé, A. \& Wang, H. CGI-58: versatile regulator of intracellular lipid droplet homeostasis. Adv. Exp. Med. Biol. 1276, 197-222 (2020).

113. Gandotra, S. et al. Perilipin deficiency and autosomal dominant partial lipodystrophy. N. Engl. J. Med. 364, 740-748 (2011).

114. Gandotra, S. et al. Human frame shift mutations affecting the carboxyl terminus of perilipin increase lipolysis by failing to sequester the adipose triglyceride lipase (ATGL) coactivator AB-hydrolase-containing 5 (ABHD5). J. Biol. Chem. 286, 34998-35006 (2011).

115. Wang, $H$. et al. Unique regulation of adipose triglyceride lipase (ATGL) by perilipin 5, a lipid droplet-associated protein. J. Biol. Chem. 286, 15707-15715 (2011)

116. Granneman, J. G., Moore, H. P., Mottillo, E. P., Zhu, Z. \& Zhou, L. Interactions of perilipin-5 (Plin5) with adipose triglyceride lipase. J. Biol. Chem. 286, 5126-5135 (2011).

117. Pollak, N. M. et al. The interplay of protein kinase A and perilipin 5 regulates cardiac lipolysis. J. Biol. Chem. 290, 1295-1306 (2015).

118. Keenan, S. N. et al. Perilipin 5 S155 phosphorylation by PKA is required for the control of hepatic lipid metabolism and glycemic control. J. Lipid Res. 62, 100016 (2021).

119. Kuramoto, K. et al. Deficiency of a lipid droplet protein, perilipin 5, suppresses myocardial lipid accumulation, thereby preventing type 1 diabetes-induced heart malfunction. Mol. Cell. Biol. 34, 2721-2731 (2014).

120. Kolleritsch, S. et al. Low cardiac lipolysis reduces mitochondrial fission and prevents lipotoxic heart dysfunction in perilipin 5 mutant mice. Cardiovasc Res. 116, 339-352 (2020).

121. Patel, S., Yang, W., Kozusko, K., Saudek, V. \& Savage, D. B. Perilipins 2 and 3 lack a carboxy-terminal domain present in perilipin 1 involved in sequestering ABHD5 and suppressing basal lipolysis. Proc. Natl Acad. Sci. USA 111, 9163-9168 (2014).

122. Petersen, M. C. \& Shulman, G. I. Mechanisms of insulin action and insulin resistance. Physiol. Rev. 98, 2133-2223 (2018).

123. DiPilato, L. M. et al. The role of PDE3B phosphorylation in the inhibition of lipolysis by insulin. Mol. Cell. Biol. 35, 2752-2760 (2015).

124. Xia, W. et al. Loss of ABHD15 impairs the anti-lipolytic action of insulin by altering PDE3B stability and contributes to insulin resistance. Cell Rep. 23, 1948-1961 (2018).

125. Vannucci, S. J., Klim, C. M., Martin, L. F. \& LaNoue, K. F. A1-adenosine receptor-mediated inhibition of adipocyte adenylate cyclase and lipolysis in Zucker rats. Am. J. Physiol. 257, E871-E878 (1989).

126. Ceddia, R. B. The role of AMP-activated protein kinase in regulating white adipose tissue metabolism. Mol. Cell. Endocrinol. 366, 194-203 (2013).

127. Mottillo, E. P. et al. Lack of adipocyte AMPK exacerbates insulin resistance and hepatic steatosis through brown and beige adipose tissue function. Cell Metab. 24, 118-129 (2016).

128. Chen, G., Zhou, G., Lotvola, A., Granneman, J. G. \& Wang, J. ABHD5 suppresses cancer cell anabolism through lipolysis-dependent activation of the AMPK/mTORC1 pathway. J. Biol. Chem. 296, jbc.RA120.014682 (2021).

129. Xie, H. et al. Adipose triglyceride lipase activity regulates cancer cell proliferation via AMP-kinase and mTOR signaling. Biochim. Biophys. Acta Mol. Cell Biol. Lipids 1865, 158737 (2020).

130. Rohm, M. et al. An AMP-activated protein kinase-stabilizing peptide ameliorates adipose tissue wasting in cancer cachexia in mice. Nat. Med. 22, $1120-1130$ (2016)

131. Lord, C. C., Thomas, G. \& Brown, J. M. Mammalian alpha beta hydrolase domain (ABHD) proteins: lipid metabolizing enzymes at the interface of cell signaling and energy metabolism. Biochim. Biophys. Acta 1831, 792-802 (2013).

132. Boeszoermenyi, A. et al. Structure of a CGI-58 motif provides the molecular basis of lipid droplet anchoring. J. Biol. Chem. 290 26361-26372 (2015)

133. Sanders, M. A., Zhang, H., Mladenovic, L., Tseng, Y. Y. \& Granneman, J. G. Molecular basis of ABHD5 lipolysis activation. Sci. Rep. 7, 42589 (2017).

134. Sanders, M. A. et al. Endogenous and synthetic ABHD5 ligands regulate ABHD5-perilipin interactions and lipolysis in fat and muscle. Cell Metab. 22, 851-860 (2015). 
135. Radner, F. P. W. et al. Growth retardation, impaired triacylglycerol catabolism, hepatic steatosis, and lethal skin barrier defect in mice lacking comparative gene identification-58 (CGI-58). J. Biol. Chem. 285 , 7300-7311 (2010).

136. Lefèvre, C. et al. Mutations in CGI-58, the gene encoding a new protein of the esterase/lipase/thioesterase subfamily, in Chanarin-Dorfman syndrome. Am. J. Hum. Genet. 69, 1002-1012 (2001).

137. Schweiger, M., Lass, A., Zimmermann, R., Eichmann, T. O. \& Zechner, R. Neutral lipid storage disease: genetic disorders caused by mutations in adipose triglyceride lipase/PNPLA2 or CGI-58/ABHD5. Am. J. Physiol. Endocrinol. Metab. 297, E289-E296 (2009).

138. Kien, B. et al. ABHD5 stimulates PNPLA1-mediated $O$-acylceramide biosynthesis essential for a functional skin permeability barrier. J. Lipid Res. 59, 2360-2367 (2018).

139. Ohno, Y., Nara, A., Nakamichi, S. \& Kihara, A. Molecular mechanism of the ichthyosis pathology of Chanarin-Dorfman syndrome: stimulation of PNPLA1-catalyzed $\omega$-O-acylceramide production by ABHD5. J. Dermatol Sci. 92, 245-253 (2018)

140. Yang, A., Mottillo, E. P., Mladenovic-Lucas, L., Zhou, L. \& Granneman, J. G. Dynamic interactions of ABHD5 with PNPLA3 regulate triacylglycerol metabolism in brown adipocytes. Nat. Metab. 1, 560-569 (2019).

141. Montero-Moran, G. et al. CGI-58/ABHD5 is a coenzyme A-dependent lysophosphatidic acid acyltransferase. J. Lipid Res. 51, 709-719 (2010).

142. Jebessa, Z. H. et al. The lipid droplet-associated protein ABHD5 protects the heart through proteolysis of HDAC4. Nat. Metab. 1, 1157-1167 (2019).

143. Russell, L. \& Forsdyke, D. R. A human putative lymphocyte G0/G1 switch gene containing a CpG-Rich island encodes a small basic protein with the potential to be phosphorylated. DNA Cell Biol. 10, 581-591 (1991).

144. Heckmann, B. L., Zhang, X., Xie, X. \& Liu, J. The G0/G1 switch gene 2 (G0S2): regulating metabolism and beyond. Biochim. Biophys. Acta 1831, 276-281 (2013).

145. Yang, X. et al. The G0/G1 switch gene 2 regulates adipose lipolysis through association with adipose triglyceride lipase. Cell Metab. 11, 194-205 (2010).

146. Zhang, X., Heckmann, B. L., Campbell, L. E. \& Liu, J. G0S2: A small giant controller of lipolysis and adipose-liver fatty acid flux. Biochim. Biophys. Acta Mol. Cell. Biol. Lipids 1862, 1146-1154 (2017).

147. Lu, X., Yang, X. \& Liu, J. Differential control of ATGL-mediated lipid droplet degradation by CGI-58 and G0S2. Cell Cycle 9, 2719-2725 (2010).

148. Cerk, I. K. et al. A peptide derived from G0/G1 switch gene 2 acts as noncompetitive inhibitor of adipose triglyceride lipase. J. Biol. Chem. 289, 32559-32570 (2014).

149. Zhang, X. et al. Identification of an intrinsic lysophosphatidic acid acyltransferase activity in the lipolytic inhibitor G0/G1 switch gene 2 (G0S2). FASEB J. 33, 6655-6666 (2019).

150. Zandbergen, F. et al. The G0/G1 switch gene 2 is a novel PPAR target gene. Biochem. J. 392, 313-324 (2005).

151. Heckmann, B. L. et al. Liver X receptor $\alpha$ mediates hepatic triglyceride accumulation through upregulation of G0/G1 switch gene 2 expression. JCI Insight 2, e88735 (2017).

152. Heier, C. et al. G0/G1 switch gene 2 regulates cardiac lipolysis. J. Biol. Chem. 290, 26141-26150 (2015).

153. Heckmann, B. L. et al. Defective adipose lipolysis and altered global energy metabolism in mice with adipose overexpression of the lipolytic Inhibitor G0/G1 switch gene 2 (G0S2). J. Biol. Chem. 289, 1905-1916 (2014).

154. Ma, T. et al. Mice lacking G0S2 are lean and cold-tolerant. Cancer Biol. Ther. 15, 643-650 (2014).

155. El-Assaad, W. et al. Deletion of the gene encoding G0/G 1 switch protein 2 (G0s2) alleviates high-fat-diet-induced weight gain and insulin resistance, and promotes browning of white adipose tissue in mice. Diabetologia $\mathbf{5 8}$, 149-157 (2015).

156. Zhang, X. et al. Targeted disruption of G0/G1 switch gene 2 enhances adipose lipolysis, alters hepatic energy balance, and alleviates high-fat diet-induced liver steatosis. Diabetes 63, 934-946 (2014).

157. Denko, N. et al. Epigenetic regulation of gene expression in cervical cancer cells by the tumor microenvironment. Clin. Cancer Res. 6, 480-487 (2000).

158. Gimm, T. et al. Hypoxia-inducible protein 2 is a novel lipid droplet protein and a specific target gene of hypoxia-inducible factor-1. FASEB J. 24, 4443-4458 (2010).

159. Mattijssen, F. et al. Hypoxia-inducible lipid droplet-associated (HILPDA) is a novel peroxisome proliferator-activated receptor (PPAR) target involved in hepatic triglyceride secretion. J. Biol. Chem. 289, 19279-19293 (2014).

160. de la Rosa Rodriguez, M. A. \& Kersten, S. Regulation of lipid droplet homeostasis by hypoxia inducible lipid droplet associated HILPDA. Biochim. Biophys. Acta Mol. Cell. Biol. Lipids 1865, 158738 (2020).

161. DiStefano, M. T. et al. The lipid droplet protein hypoxia-inducible gene 2 promotes hepatic triglyceride deposition by inhibiting lipolysis. J. Biol. Chem. 290, 15175-15184 (2015).

162. Zhang, X. et al. Inhibition of intracellular lipolysis promotes human cancer cell adaptation to hypoxia. eLife 6, e31132 (2017)
163. Padmanabha Das, K. M. et al. Hypoxia-inducible lipid droplet-associated protein inhibits adipose triglyceride lipase. J. Lipid Res. 59, 531-541 (2018).

164. de la Rosa Rodriguez, M. A. et al. Hypoxia-inducible lipid droplet-associated induces DGAT1 and promotes lipid storage in hepatocytes. Mol. Metab. 47, 101168 (2021).

165. Dijk, W. et al. Hypoxia-inducible lipid droplet-associated Is not a direct physiological regulator of lipolysis in adipose tissue. Endocrinology 158, 1231-1251 (2017)

166. DiStefano, M. T. et al. Adipocyte-specific hypoxia-inducible gene 2 promotes fat deposition and diet-induced insulin resistance. Mol. Metab. 5, 1149-1161 (2016).

167. Hofer, P., Taschler, U., Schreiber, R., Kotzbeck, P. \& Schoiswohl, G. The lipolysome-a highly complex and dynamic protein network orchestrating cytoplasmic triacylglycerol degradation. Metabolites 10, 147 (2020).

168. Smith, A. J. et al. Physical association between the adipocyte fatty acid-binding protein and hormone-sensitive lipase: a fluorescence resonance energy transfer analysis. J. Biol. Chem. 279, 52399-52405 (2004).

169. Gillilan, R. E., Ayers, S. D. \& Noy, N. Structural basis for activation of fatty acid-binding protein 4. J. Mol. Biol. 372, 1246-1260 (2007).

170. Mahadevan, S. \& Tappel, A. L. Lysosomal lipases of rat liver and kidney. J. Biol. Chem. 243, 2849-2854 (1968).

171. Grumet, L. et al. Lysosomal acid lipase hydrolyzes retinyl ester and affects retinoid turnover. J. Biol. Chem. 291, 17977-17987 (2016).

172. Sheriff, S., Du, H. \& Grabowski, G. A. Characterization of lysosomal acid lipase by site-directed mutagenesis and heterologous expression. J. Biol. Chem. 270, 27766-27772 (1995).

173. Warner, T. G., Dambach, L. M., Shin, J. H. \& O’Brien, J. S. Purification of the lysosomal acid lipase from human liver and its role in lysosomal lipid hydrolysis. J. Biol. Chem. 256, 2952-2957 (1981).

174. Ameis, D., Merkel, M., Eckerskorn, C. \& Greten, H. Purification, characterization and molecular cloning of human hepatic lysosomal acid lipase. Eur. J. Biochem. 219, 905-914 (1994).

175. Rajamohan, F. et al. Crystal structure of human lysosomal acid lipase and its implications in cholesteryl ester storage disease. J. Lipid Res. 61, 1192-1202 (2020).

176. Zechner, R., Madeo, F. \& Kratky, D. Cytosolic lipolysis and lipophagy: two sides of the same coin. Nat. Rev. Mol. Cell Biol. 18, 671-684 (2017).

177. Sando, G. N. \& Henke, V. L. Recognition and receptor-mediated endocytosis of the lysosomal acid lipase secreted by cultured human fibroblasts. J. Lipid Res. 23, 114-123 (1982).

178. Haka, A. S. et al. Macrophages create an acidic extracellular hydrolytic compartment to digest aggregated lipoproteins. Mol. Biol. Cell 20, 4932-4940 (2009).

179. Singh, R. K. et al. Degradation of aggregated LDL occurs in complex extracellular sub-compartments of the lysosomal synapse. J. Cell Sci. 129, 1072-1082 (2016).

180. Leake, D. S. Does an acidic $\mathrm{pH}$ explain why low density lipoprotein is oxidised in atherosclerotic lesions? Atherosclerosis 129, 149-157 (1997).

181. Pajed, L. et al. Hepatocyte-specific deletion of lysosomal acid lipase leads to cholesteryl ester but not triglyceride or retinyl ester accumulation. J. Biol. Chem. 294, 9118-9133 (2019).

182. Burton, B. K. et al. A phase 3 trial of sebelipase alfa in lysosomal acid lipase deficiency. N. Engl. J. Med. 373, 1010-1020 (2015).

183. Ikonen, E. Cellular cholesterol trafficking and compartmentalization. Nat. Rev. Mol. Cell Biol. 9, 125-138 (2008).

184. Goldstein, J. L. \& Brown, M. S. A century of cholesterol and coronaries: from plaques to genes to statins. Cell 161, 161-172 (2015).

185. Radović, B. et al. Lysosomal acid lipase regulates VLDL synthesis and insulin sensitivity in mice. Diabetologia 59, 1743-1752 (2016).

186. Huang, S. C. C. et al. Cell-intrinsic lysosomal lipolysis is essential for alternative activation of macrophages. Nat. Immunol. 15, 846-855 (2014).

187. Schlager, S. et al. Lysosomal lipid hydrolysis provides substrates for lipid mediator synthesis in murine macrophages. Oncotarget $\mathbf{8}$, 40037-40051 (2017)

188. Duta-Mare, M. et al. Lysosomal acid lipase regulates fatty acid channeling in brown adipose tissue to maintain thermogenesis. Biochim. Biophys. Acta Mol. Cell. Biol. Lipids 1863, 467-478 (2018).

189. Singh, R. et al. Autophagy regulates lipid metabolism. Nature 458, 1131-1135 (2009)

190. Ouimet, M. et al. Autophagy regulates cholesterol efflux from macrophage foam cells via lysosomal acid lipase. Cell Metab. 13, 655-667 (2011).

191. Cui, W. et al. Lipophagy-derived fatty acids undergo extracellular efflux via lysosomal exocytosis. Autophagy 17, 690-705 (2021).

192. Schulze, R. J., Sathyanarayan, A. \& Mashek, D. G. Breaking fat: the regulation and mechanisms of lipophagy. Biochim. Biophys. Acta Mol. Cell. Biol. Lipids 1862, 1178-1187 (2017).

193. Mijaljica, D., Prescott, M. \& Devenish, R. J. Microautophagy in mammalian cells: revisiting a 40-year-old conundrum. Autophagy 7, 673-682 (2011). 
194. Schulze, R. J. et al. Direct lysosome-based autophagy of lipid droplets in hepatocytes. Proc. Natl Acad. Sci. USA 117, 32443-32452 (2020).

195. Schott, M. B. et al. Lipid droplet size directs lipolysis and lipophagy catabolism in hepatocytes. J. Cell Biol. 218, 3320-3335 (2019).

196. Kaushik, S. \& Cuervo, A. M. Degradation of lipid droplet-associated proteins by chaperone-mediated autophagy facilitates lipolysis. Nat. Cell Biol. 17, 759-770 (2015)

197. Fred Dice, J. Peptide sequences that target cytosolic proteins for lysosomal proteolysis. Trends Biochem. Sci. 15, 305-309 (1990).

198. Chiang, H. L., Terlecky, S. R., Plant, C. P. \& Dice, J. F. A role for a 70-kilodaton heat shock protein in lysosomal degradation of intracellular proteins. Science 246, 382-385 (1989).

199. Du, H., Duanmu, M., Witte, D. \& Grabowski, G. A. Targeted disruption of the mouse lysosomal acid lipase gene: long-term survival with massive cholesteryl ester and triglyceride storage. Hum. Mol. Genet. 7, 1347-1354 (1998).

200. Du, H. et al. Lysosomal acid lipase-deficient mice: depletion of white and brown fat, severe hepatosplenomegaly, and shortened life span. J. Lipid Res. 42, 489-500 (2001)

201. Patrick, A. D. \& Lake, B. D. Deficiency of an acid lipase in wolman's disease. Nature 222, 1067-1068 (1969).

202. Burke, J. A. \& Schubert, W. K. Deficient activity of hepatic acid lipase in cholesterol ester storage disease. Science 176, 309-310 (1972).

203. Bernstein, D. L., Hülkova, H., Bialer, M. G. \& Desnick, R. J. Cholesteryl ester storage disease: review of the findings in 135 reported patients with an underdiagnosed disease. J. Hepatol. 58, 1230-1243 (2013).

204. Wild, P. S. et al. A genome-wide association study identifies LIPA as a susceptibility gene for coronary artery disease. Circ. Cardiovasc. Genet. 4, 403-412 (2011).

205. Schweiger, M. et al. Adipose triglyceride lipase and hormone-sensitive lipase are the major enzymes in adipose tissue triacylglycerol catabolism. J. Biol. Chem. 281, 40236-40241 (2006).

206. Pichery, M. et al. PNPLAl defects in patients with autosomal recessive congenital ichthyosis and KO mice sustain PNPLA1 irreplaceable function in epidermal omega- $O$-acylceramide synthesis and skin permeability barrier. Hum. Mol. Genet. 26, 1787-1800 (2017).

207. Hirabayashi, T. et al. PNPLA1 has a crucial role in skin barrier function by directing acylceramide biosynthesis. Nat. Commun. 8, 14609 (2017).

208. Grall, A. et al. PNPLA1 mutations cause autosomal recessive congenital ichthyosis in golden retriever dogs and humans. Nat. Genet. 44, 140-147 (2012).

209. Onal, G. et al. Impairment of lipophagy by PNPLA1 mutations causes lipid droplet accumulation in primary fibroblasts of Autosomal Recessive Congenital Ichthyosis patients. J. Dermatol. Sci. 93, 50-57 (2019).

210. Wilson, P. A., Gardner, S. D., Lambie, N. M., Commans, S. A. \& Crowther, D. J. Characterization of the human patatin-like phospholipase family. J. Lipid Res. 47, 1940-1949 (2006).

211. Baulande, S., Lasnier, F., Lucas, M. \& Pairault, J. Adiponutrin, a transmembrane protein corresponding to a novel dietary- and obesity-linked mRNA specifically expressed in the adipose Lineage. J. Biol. Chem. 276, 33336-33344 (2001).

212. Dubuquoy, C. et al. Distinct regulation of adiponutrin/PNPLA3 gene expression by the transcription factors ChREBP and SREBP1c in mouse and human hepatocytes. J. Hepatol. 55, 145-153 (2011)

213. He, S. et al. A sequence variation (I148M) in PNPLA3 associated with nonalcoholic fatty liver disease disrupts triglyceride hydrolysis. J. Biol. Chem. 285, 6706-6715 (2010).

214. Pirazzi, C. et al. PNPLA3 has retinyl-palmitate lipase activity in human hepatic stellate cells. Hum. Mol. Genet. 23, 4077-4085 (2014).

215. Huang, Y., Cohen, J. C. \& Hobbs, H. H. Expression and characterization of a PNPLA3 protein isoform (I148M) associated with nonalcoholic fatty liver disease. J. Biol. Chem. 286, 37085-37093 (2011).

216. Kumari, M. et al. Adiponutrin functions as a nutritionally regulated lysophosphatidic acid acyltransferase. Cell Metab. 15, 691-702 (2012).

217. Dong, X. C. PNPLA3-a potential therapeutic target for personalized treatment of chronic liver disease. Front. Med. 6, 304 (2019).

218. Basantani, M. K. et al. Pnpla3/adiponutrin deficiency in mice does not contribute to fatty liver disease or metabolic syndrome. J. Lipid Res. 52, 318-329 (2011).

219. Chen, W., Chang, B., Li, L. \& Chan, L. Patatin-like phospholipase domain-containing 3/adiponutrin deficiency in mice is not associated with fatty liver disease. Hepatology 52, 1134-1142 (2010).

220. Romeo, S. et al. Genetic variation in PNPLA3 confers susceptibility to nonalcoholic fatty liver disease. Nat. Genet. 40, 1461-1465 (2008).

221. Wang, Y., Kory, N., BasuRay, S., Cohen, J. C. \& Hobbs, H. H. PNPLA3, CGI-58, and inhibition of hepatic triglyceride hydrolysis in Mice. Hepatology 69, hep.30583 (2019)
222. BasuRay, S., Smagris, E., Cohen, J. C. \& Hobbs, H. H. The PNPLA3 variant associated with fatty liver disease (I148M) accumulates on lipid droplets by evading ubiquitylation. Hepatology 66, 1111-1124 (2017).

223. Negoita, F. et al. PNPLA3 variant M148 causes resistance to starvation-mediated lipid droplet autophagy in human hepatocytes. J. Cell. Biochem. 120, 343-356 (2019).

224. Lee, W. C., Salido, E. \& Yen, P. H. Isolation of a new gene GS2 (DXS1283E) from a CpG island between STS and KAL1 on xp22.3. Genomics 22, 372-376 (1994).

225. Lake, A. C. et al. Expression, regulation, and triglyceride hydrolase activity of adiponutrin family members. J. Lipid Res. 46, 2477-2487 (2005).

226. Gao, J. \& Simon, M. Identification of a novel keratinocyte retinyl ester hydrolase as a transacylase and lipase. J. Invest. Dermatol. 124, 1259-1266 (2005)

227. Kohda, M. et al. A comprehensive genomic analysis reveals the genetic landscape of mitochondrial respiratory chain complex deficiencies. PLoS Genet. 12, e1005679 (2016).

228. Labonne, J. D. J. et al. Comparative genomic mapping implicates LRRK2 for intellectual disability and autism at $12 \mathrm{q} 12$, and HDHD1, as well as PNPLA4, for X-linked intellectual disability at Xp22.31. J. Clin. Med. 9, $274(2020)$

229. Kornahrens, A. F. et al. Design of benzoxathiazin-3-one 1,1-dioxides as a new class of irreversible serine hydrolase inhibitors: discovery of a uniquely selective PNPLA4 inhibitor. J. Am. Chem. Soc. 139, 7052-7061 (2017).

230. Gao, J. G. \& Simon, M. A comparative study of human GS2, its paralogues, and its rat orthologue. Biochem. Biophys. Res. Commun. 360, 501-506 (2007).

231. Dupont, N. et al. Neutral lipid stores and lipase PNPLA5 contribute to autophagosome biogenesis. Curr. Biol. 24, 609-620 (2014).

232. Lange, L. A. et al. Whole-exome sequencing identifies rare and low-frequency coding variants associated with LDL cholesterol. Am. J. Hum. Genet. 94, 233-245 (2014).

233. Lian, J., Nelson, R. \& Lehner, R. Carboxylesterases in lipid metabolism: from mouse to human. Protein Cell 9, 178-195 (2018).

234. Holmes, R. S. et al. Recommended nomenclature for five mammalian carboxylesterase gene families: human, mouse, and rat genes and proteins. Mamm. Genome 21, 427-441 (2010).

235. Wang, D. et al. Human carboxylesterases: a comprehensive review. Acta Pharm. Sin. B 8, 699-712 (2018).

236. Zhao, B., Fisher, B. J., St Clair, R. W., Rudel, L. L. \& Ghosh, S. Redistribution of macrophage cholesteryl ester hydrolase from cytoplasm to lipid droplets upon lipid loading. J. Lipid Res. 46, 2114-2121 (2005)

237. Ghosh, S., St Clair, R. W. \& Rudel, L. L. Mobilization of cytoplasmic CE droplets by overexpression of human macrophage cholesteryl ester hydrolase. J. Lipid Res. 44, 1833-1840 (2003).

238. Xu, Y. et al. Hepatocyte-specific expression of human carboxylesterase 1 attenuates diet-induced steatohepatitis and hyperlipidemia in mice. Hepatol. Commun. 4, 527-539 (2020).

239. Bie, J. et al. Liver-specific transgenic expression of cholesteryl ester hydrolase reduces atherosclerosis in $L D L R^{-1-}$ mice. J. Lipid Res. 55, 729-738 (2014).

240. Zhao, B. et al. Macrophage-specific transgenic expression of cholesteryl ester hydrolase significantly reduces atherosclerosis and lesion necrosis in Ldlr $^{-1-}$ mice. J. Clin. Invest. 117, 2983-2992 (2007).

241. Crow, J. A. et al. Inhibition of carboxylesterase 1 is associated with cholesteryl ester retention in human THP-1 monocyte/macrophages. Biochim. Biophys. Acta Mol. Cell Biol. Lipids 1781, 643-654 (2008).

242. Igarashi, M. et al. The critical role of neutral cholesterol ester hydrolase 1 in cholesterol removal from human macrophages. Circ. Res. 107, 1387-1395 (2010)

243. Dolinsky, V. W., Sipione, S., Lehner, R. \& Vance, D. E. The cloning and expression of a murine triacylglycerol hydrolase cDNA and the structure of its corresponding gene. Biochim. Biophys. Acta 1532, 162-172 (2001).

244. Gilham, D., Alam, M., Gao, W., Vance, D. E. \& Lehner, R. Triacylglycerol hydrolase is localized to the endoplasmic reticulum by an unusual retrieval sequence where it participates in VLDL assembly without utilizing VLDL lipids as substrates. Mol. Biol. Cell 16, 984-996 (2005).

245. Soni, K. G. et al. Carboxylesterase 3 (EC 3.1.1.1) is a major adipocyte lipase. J. Biol. Chem. 279, 40683-40689 (2004).

246. Wei, E., Gao, W. \& Lehner, R. Attenuation of adipocyte triacylglycerol hydrolase activity decreases basal fatty acid efflux. J. Biol. Chem. 282, 8027-8035 (2007)

247. Gilham, D. et al. Inhibitors of hepatic microsomal triacylglycerol hydrolase decrease very low density lipoprotein secretion. FASEB J. 17, 1685-1687 (2003)

248. Lehner, R., Lian, J. \& Quiroga, A. D. Lumenal lipid metabolism: implications for lipoprotein assembly. Arterioscler. Thromb. Vasc. Biol. 32, 1087-1093 (2012) 
249. Wei, E. et al. Apolipoprotein B and triacylglycerol secretion in human triacylglycerol hydrolase transgenic mice. J. Lipid Res. 48, 2597-2606 (2007).

250. Lian, J. et al. Liver specific inactivation of carboxylesterase $3 /$ triacylglycerol hydrolase decreases blood lipids without causing severe steatosis in mice. Hepatology 56, 2154-2162 (2012).

251. Wei, E. et al. Loss of TGH/Ces3 in mice decreases blood lipids, improves glucose tolerance, and increases energy expenditure. Cell Metab. 11, 183-193 (2010).

252. Lian, J. et al. Ces3/TGH deficiency attenuates steatohepatitis. Sci. Rep. 6, 25747 (2016)

253. Lian, J., van der Veen, J. N., Watts, R., Jacobs, R. L. \& Lehner, R. Carboxylesterase 1d (Ces1d) does not contribute to cholesteryl ester hydrolysis in the liver. J. Lipid Res. 62, 100093 (2021).

254. Ko, K. W. S., Erickson, B. \& Lehner, R. Es-x/Ces1 prevents triacylglycerol accumulation in McArdle-RH7777 hepatocytes. Biochim. Biophys. Acta Mol. Cell Biol. Lipids 1791, 1133-1143 (2009).

255. Xu, J. et al. Hepatic carboxylesterase 1 is essential for both normal and farnesoid X receptor-controlled lipid homeostasis. Hepatology 59, 1761-1771 (2014).

256. Quiroga, A. D. et al. Deficiency of carboxylesterase 1/esterase-x results in obesity, hepatic steatosis, and hyperlipidemia. Hepatology 56, 2188-2198 (2012).

257. Bahitham, W., Watts, R., Nelson, R., Lian, J. \& Lehner, R. Liver-specific expression of carboxylesterase $1 \mathrm{~g} /$ esterase-x reduces hepatic steatosis, counteracts dyslipidemia and improves insulin signaling. Biochim. Biophys. Acta Mol. Cell Biol. Lipids 1861, 482-490 (2016).

258. Li, Y. et al. Carboxylesterase 2 prevents liver steatosis by modulating lipolysis, endoplasmic reticulum stress, and lipogenesis and is regulated by hepatocyte nuclear factor 4 alpha in mice. Hepatology 63, 1860-1874 (2016)

259. Ruby, M. A. et al. Human carboxylesterase 2 reverses obesity-induced diacylglycerol accumulation and glucose intolerance. Cell Rep. 18, 636-646 (2017).

260. Xu, Y. et al. Hepatocyte-specific expression of human carboxylesterase 2 attenuates nonalcoholic steatohepatitis in mice. Am. J. Physiol. Liver Physiol. 320, G166-G174 (2021).

261. Chalhoub, G. et al. Carboxylesterase 2 proteins are efficient diglyceride and monoglyceride lipases possibly implicated in metabolic disease. J. Lipid Res. 62, 100075 (2021).

262. Maresch, L. K. et al. Intestine-specific overexpression of carboxylesterase $2 c$ protects mice from diet-induced liver steatosis and obesity. Hepatol. Commun. 3, 227-245 (2019).

263. Goo, Y.-H., Son, S.-H., Kreienberg, P. B. \& Paul, A. Novel lipid droplet-associated serine hydrolase regulates macrophage cholesterol mobilization. Arterioscler. Thromb. Vasc. Biol. 34, 386-396 (2014).

264. Thiel, K. et al. The evolutionarily conserved protein CG9186 is associated with lipid droplets, required for their positioning and for fat storage. J. Cell Sci. 126, 2198-2212 (2013).

265. Kory, N. et al. Mice lacking lipid droplet-associated hydrolase, a gene linked to human prostate cancer, have normal cholesterol ester metabolism. J. Lipid Res. 58, 226-235 (2017).

266. Kolkhof, P. et al. A luciferase-fragment complementation assay to detect lipid droplet-associated protein-protein interactions. Mol. Cell. Proteom. 16, 329-345 (2017).

267. Goo, Y. H., Son, S. H. \& Paul, A. Lipid droplet-associated hydrolase promotes lipid droplet fusion and enhances ATGL degradation and triglyceride accumulation. Sci. Rep. 7, 1-13 (2017).

268. Currall, B. B. et al. Loss of LDAH associated with prostate cancer and hearing loss. Hum. Mol. Genet. 27, 4194-4203 (2018)

269. Nakajima, K. I. et al. A novel phospholipase Al with sequence homology to a mammalian Sec23p-interacting protein, p125. J. Biol. Chem. 277, 11329-11335 (2002).

270. Tani, K., Mizoguchi, T., Iwamatsu, A., Hatsuzawa, K. \& Tagaya, M. p125 Is a novel mammalian Sec23p-interacting protein with structural similarity to phospholipid-modifying proteins. J. Biol. Chem. 274, 20505-20512 (1999)

271. Araki, M. et al. Enzymatic characterization of recombinant rat DDHD2: a soluble diacylglycerol lipase. J. Biochem. 160, 269-279 (2016).

272. Aso, C. et al. Protein purification and cloning of diacylglycerol lipase from rat brain. J. Biochem. 159, 585-597 (2016).

273. Inloes, J. M. et al. The hereditary spastic paraplegia-related enzyme DDHD2 is a principal brain triglyceride lipase. Proc. Natl Acad. Sci. U. S. A. 111, 14924-14929 (2014).

274. Inloes, J. M. et al. Functional contribution of the spastic paraplegia-related triglyceride hydrolase DDHD2 to the formation and content of lipid droplets. Biochemistry 57, 827-838 (2018).

275. Morikawa, R. K. et al. Intracellular phospholipase A1 $\gamma(\mathrm{iPLA} 1 \gamma)$ is a novel factor involved in coat protein complex I-and Rab6-independent retrograde transport between the endoplasmic reticulum and the golgi complex. J. Biol. Chem. 284, 26620-26630 (2009).

276. Schuurs-Hoeijmakers, J. H. M. et al. Mutations in DDHD2, encoding an intracellular phospholipase $\mathrm{A} 1$, cause a recessive form of complex hereditary spastic paraplegia. Am. J. Hum. Genet. 91, 1073-1081 (2012).

277. Gonzalez, M. et al. Mutations in phospholipase DDHD2 cause autosomal recessive hereditary spastic paraplegia (SPG54). Eur. J. Hum. Genet. 21, 1214-1218 (2013).

278. Citterio, A. et al. Mutations in CYP2U1, DDHD2 and GBA2 genes are rare causes of complicated forms of hereditary spastic paraparesis. J. Neurol. 261, 373-381 (2014)

279. Maruyama, T. et al. Loss of DDHD2, whose mutation causes spastic paraplegia, promotes reactive oxygen species generation and apoptosis. Cell Death Dis. 9, 1-15 (2018).

280. Yang, L. et al. Neuronal lipolysis participates in PUFA-mediated neural function and neurodegeneration. EMBO Rep. 21, e50214 (2020).

281. Yang, C. et al. Rewiring neuronal glycerolipid metabolism determines the extent of axon regeneration. Neuron 105, 276-292.e5 (2020).

282. Park, C. Y. et al. Genome-wide landscape of RNA-binding protein target site dysregulation reveals a major impact on psychiatric disorder risk. Nat. Genet. 53, 166-173 (2021).

283. Matoba, N. et al. Common genetic risk variants identified in the SPARK cohort support DDHD2 as a candidate risk gene for autism. Transl. Psychiatry 10, 265 (2020).

284. Probst, M. R. et al. Human liver arylacetamide deacetylase. Molecular cloning of a novel esterase involved in the metabolic activation of arylamine carcinogens with high sequence similarity to hormone-sensitive lipase. J. Biol. Chem. 269, 21650-21656 (1994).

285. Trickett, J. I. et al. Characterization of the rodent genes for arylacetamide deacetylase, a putative microsomal lipase, and evidence for transcriptional regulation. J. Biol. Chem. 276, 39522-39532 (2001).

286. Lo, V. et al. Arylacetamide deacetylase attenuates fatty-acid-induced triacylglycerol accumulation in rat hepatoma cells. J. Lipid Res. 51, 368-377 (2010).

287. Tiwari, R., Köffel, R. \& Schneiter, R. An acetylation/deacetylation cycle controls the export of sterols and steroids from S. cerevisiae. EMBO J. 26, 5109-5119 (2007)

288. Gibbons, G. F., Islam, K. \& Pease, R. J. Mobilisation of triacylglycerol stores. Biochim. Biophys. Acta Mol. Cell Biol. Lipids 1483, 37-57 (2000).

289. Lee, H. et al. Compositional dynamics of the milk fat globule and its role in infant development. Front. Pediatr. 6, 313 (2018)

290. Van Niel, G., D’Angelo, G. \& Raposo, G. Shedding light on the cell biology of extracellular vesicles. Nat. Rev. Mol. Cell Biol. 19 213-228 (2018).

291. Raposo, G. \& Stoorvogel, W. Extracellular vesicles: exosomes, microvesicles, and friends. J. Cell Biol. 200, 373-383 (2013).

292. Flaherty, S. E. et al. A lipase-independent pathway of lipid release and immune modulation by adipocytes. Science. 363, 989-993 (2019).

293. Schneider, M. R. Lipid droplets and associated proteins in sebocytes. Exp. Cell. Res. 340, 205-208 (2016).

294. Choa, R. et al. Thymic stromal lymphopoietin induces adipose loss through sebum hypersecretion. Science 373, eabd2893 (2021).

295. Zimmet, P., Alberti, K. G., Magliano, D. J. \& Bennett, P. H. Diabetes mellitus statistics on prevalence and mortality: facts and fallacies. Nat. Rev. Endocrinol. 12, 616-622 (2016).

296. Morigny, P., Houssier, M., Mouisel, E. \& Langin, D. Adipocyte lipolysis and insulin resistance. Biochimie 125, 259-266 (2016).

297. Hoy, A. J. et al. Adipose triglyceride lipase-null mice are resistant to high-fat diet-induced insulin resistance despite reduced energy expenditure and ectopic lipid accumulation. Endocrinology 152, 48-58 (2011).

298. Schoiswohl, G. et al. Impact of reduced ATGL-mediated adipocyte lipolysis on obesity-associated insulin resistance and inflammation in male mice. Endocrinology 156, 3610-3624 (2015).

299. Xia, B. et al. Adipose tissue deficiency of hormone-sensitive lipase causes fatty liver in mice. PLoS Genet. 13, 1-17 (2017)

300. Schweiger, M. et al. Pharmacological inhibition of adipose triglyceride lipase corrects high-fat diet-induced insulin resistance and hepatosteatosis in mice. Nat. Commun. 8, 14859 (2017).

301. Girousse, A. et al. Partial inhibition of adipose tissue lipolysis improves glucose metabolism and insulin sensitivity without alteration of fat mass. PLoS Biol. 11, e1001485 (2013).

302. Perry, R. J. et al. Hepatic acetyl CoA links adipose tissue inflammation to hepatic insulin resistance and type 2 diabetes. Cell 160, 1-14 (2015).

303. Prentki, M., Matschinsky, F. M. \& Madiraju, S. R. M. Metabolic signaling in fuel-induced insulin secretion. Cell Metab. 18, 162-185 (2013).

304. Peyot, M.-L. et al. Adipose triglyceride lipase is implicated in fueland non-fuel-stimulated insulin secretion. J. Biol. Chem. 284 16848-16859 (2009) 
305. Liu, S. et al. Adipose triglyceride lipase is a key lipase for the mobilization of lipid droplets in human beta cells and critical for the maintenance of Syntaxinla level in beta cells. Diabetes 69, 1178-1192 (2020).

306. Fex, M. et al. A beta cell-specific knockout of hormone-sensitive lipase in mice results in hyperglycaemia and disruption of exocytosis. Diabetologia 52, 271-280 (2009).

307. Roduit, R. et al. A role for hormone-sensitive lipase in glucose-stimulated insulin secretion: a study in hormone-sensitive lipase-deficient mice. Diabetes 50, 1970-1975 (2001).

308. Pearson, G. L. et al. Lysosomal acid lipase and lipophagy are constitutive negative regulators of glucose-stimulated insulin secretion from pancreatic beta cells. Diabetologia 57, 129-139 (2014).

309. Zhao, S. et al. $\alpha / \beta$-hydrolase domain- 6 -accessible monoacylglycerol controls glucose-stimulated insulin secretion. Cell Metab. 6, 1-15 (2014).

310. Scheja, L. et al. Altered insulin secretion associated with reduced lipolytic efficiency in $a P 2^{-/-}$mice. Diabetes 48, 1987-1994 (1999).

311. Wu, J. W. et al. Fasting energy homeostasis in mice with adipose deficiency of desnutrin/adipose triglyceride lipase. Endocrinology 153, 2198-2207 (2012)

312. Mitra, S., De, A. \& Chowdhury, A. Epidemiology of non-alcoholic and alcoholic fatty liver diseases. Transl. Gastroenterol. Hepatol. 5, 16 (2020).

313. Kim, D., Touros, A. \& Kim, W. R. Nonalcoholic fatty liver disease and metabolic syndrome. Clin. Liver Dis. 22, 133-140 (2018).

314. Donnelly, K. L. et al. Sources of fatty acids stored in liver and secreted via lipoproteins in patients with nonalcoholic fatty liver disease. J. Clin. Invest. 115, 1343-1351 (2005)

315. Jaeger, D. et al. Fasting-induced G0/G1 switch gene 2 and FGF21 expression in the liver are under regulation of adipose tissue derived fatty acids. J. Hepatol. 63, 437-445 (2015).

316. Ahmadian, M. et al. Adipose overexpression of desnutrin promotes fatty acid use and attenuates diet-induced obesity. Diabetes 58, 855-866 (2009).

317. Lindén, D. et al. Pnpla3 silencing with antisense oligonucleotides ameliorates nonalcoholic steatohepatitis and fibrosis in Pnpla3 I148M knock-in mice. Mol. Metab. 22, 49-61 (2019).

318. BasuRay, S. PNPLA3-I148M: a problem of plenty in non-alcoholic fatty liver disease. Adipocyte 8, 201-208 (2019).

319. Reid, B. N. et al. Hepatic overexpression of hormone-sensitive lipase and adipose triglyceride lipase promotes fatty acid oxidation, stimulates direct release of free fatty acids, and ameliorates steatosis. J. Biol. Chem. 283, 13087-13099 (2008)

320. Ponikowski, P. et al. 2016 ESC Guidelines for the diagnosis and treatment of acute and chronic heart failure: The Task Force for the diagnosis and treatment of acute and chronic heart failure of the European Society of Cardiology (ESC)Developed with the special contribution of the Heart Failure Association (HFA) of the ESC. Eur. Heart J. 37, 2129-2200 (2016).

321. Groenewegen, A., Rutten, F. H., Mosterd, A. \& Hoes, A. W. Epidemiology of heart failure. Eur. J. Heart Fail. 22, 1342-1356 (2020).

322. Kolwicz, S. C., Purohit, S. \& Tian, R. Cardiac metabolism and its interactions with contraction, growth, and survival of cardiomyocytes. Circ. Res. 113, 603-616 (2013).

323. Szabó, T. et al. Increased catabolic activity in adipose tissue of patients with chronic heart failure. Eur. J. Heart Fail. 15, 1131-1137 (2013).

324. Cohn, J. N. et al. Plasma norepinephrine as a guide to prognosis in patients with chronic congestive heart failure. N. Engl. J. Med. 311, 819-823 (1984).

325. Scherbakov, N. et al. Insulin resistance in heart failure: differences between patients with reduced and preserved left ventricular ejection fraction. Eur. J. Heart Fail. 17, 1015-1021 (2015).

326. Parajuli, N. et al. Atglistatin ameliorates functional decline in heart failure via adipocyte-specific inhibition of adipose triglyceride lipase. Am. J. Physiol. Circ. Physiol. 315, H879-H884 (2018).

327. Salatzki, J. et al. Adipose tissue ATGL modifies the cardiac lipidome in pressure-overload-induced left ventricular failure. PLoS Genet. 14, e1007171 (2018)

328. Thiele, A. et al. Pharmacological inhibition of adipose tissue adipose triglyceride lipase by atglistatin prevents catecholamine-induced myocardial damage. Cardiovasc. Res. cvab182 (2021)

329. Kintscher, U., Foryst-Ludwig, A., Haemmerle, G. \& Zechner, R. The role of adipose triglyceride lipase and cytosolic lipolysis in cardiac function and heart Failure. Cell Reports Med. 1, 100001 (2020).

330. Schiattarella, G. G. et al. Nitrosative stress drives heart failure with preserved ejection fraction. Nature 568, 351-356 (2019).

331. Baracos, V. E., Martin, L., Korc, M., Guttridge, D. C. \& Fearon, K. C. H. Cancer-associated cachexia. Nat. Rev. Dis. Prim. 4, 1-18 (2018)

332. Petruzzelli, M. \& Wagner, E. F. Mechanisms of metabolic dysfunction in cancer-associated cachexia. Genes Dev. 30, 489-501 (2016).

333. Das, S. K. et al. Adipose triglyceride lipase contributes to cancer-associated cachexia. Science 333, 233-238 (2011).
334. Fouladiun, M. et al. Body composition and time course changes in regional distribution of fat and lean tissue in unselected cancer patients on palliative care-correlations with food intake, metabolism, exercise capacity, and hormones. Cancer 103, 2189-2198 (2005).

335. Sun, X. et al. Fat wasting is damaging: role of adipose tissue in cancer-associated cachexia. Front. Cell Dev. Biol. 8, 1-9 (2020).

336. Petruzzelli, M. et al. A switch from white to brown fat increases energy expenditure in cancer-associated cachexia. Cell Metab. 20, 433-447 (2014).

337. Tsoli, M. et al. Depletion of white adipose tissue in cancer cachexia syndrome is associated with inflammatory signaling and disrupted circadian regulation. PLoS ONE 9, e92966 (2014).

338. Kaur, S. et al. Adipose-specific ATGL ablation reduces burn injury-induced metabolic derangements in mice. Clin. Transl. Med. 11, e417 (2021).

339. Samsa, M. M. et al. Dengue virus capsid protein usurps lipid droplets for viral particle formation. PLoS Pathog. 5, e1000632 (2009).

340. Richards, O. C. \& Ehrenfeld, E. in Poliovirus RNA Replication. 89-119 (Springer, 1990)

341. Laufman, O., Perrino, J. \& Andino, R. Viral generated inter-organelle contacts redirect lipid flux for genome replication. Cell 178, 275-289 (2019).

342. Sturley, S. L. et al. Potential COVID-19 therapeutics from a rare disease: weaponizing lipid dysregulation to combat viral infectivity. J. Lipid Res. 61, 972-982 (2020)

343. Vance, D. E., Trip, E. M. \& Paddon, H. B. Poliovirus increases phosphatidylcholine biosynthesis in HeLa cells by stimulation of the rate-limiting reaction catalyzed by CTP:phosphocholine cytidylyltransferase. J. Biol. Chem. 255, 1064-1069 (1980).

344. Nchoutmboube, J. A. et al. Increased long chain acyl-Coa synthetase activity and fatty acid import is linked to membrane synthesis for development of picornavirus replication organelles. PLoS Pathog. 9, e1003401 (2013).

345. Yen, C. L. E., Stone, S. J., Koliwad, S., Harris, C. \& Farese, R. V. DGAT enzymes and triacylglycerol biosynthesis. J. Lipid Res. 49, 2283-2301 (2008).

346. Miyanari, Y. et al. The lipid droplet is an important organelle for hepatitis C virus production. Nat. Cell Biol. 9, 1089-1097 (2007).

347. Herker, E. \& Ott, M. Unique ties between hepatitis C virus replication and intracellular lipids. Trends Endocrinol. Metab. 22, 241-248 (2011).

348. Camus, G. et al. The hepatitis $\mathrm{C}$ virus core protein inhibits adipose triglyceride lipase (ATGL)-mediated lipid mobilization and enhances the ATGL interaction with comparative gene identification 58 (CGI-58) and lipid droplets. J. Biol. Chem. 289, 35770-35780 (2014).

349. Moriya, K. et al. Hepatitis $\mathrm{C}$ virus core protein induces hepatic steatosis in transgenic mice. J. Gen. Virol. 78, 1527-1531 (1997).

350. Nardacci, R. et al. Evidences for lipid involvement in SARS-CoV-2 cytopathogenesis. Cell Death Dis. 12, 263 (2021).

351. Baazim, $\mathrm{H}$. et al. $\mathrm{CD} 8^{+} \mathrm{T}$ cells induce cachexia during chronic viral infection. Nat. Immunol. 6, 701-710 (2019).

352. Heaton, N. S. \& Randall, G. Dengue virus-induced autophagy regulates lipid metabolism. Cell Host Microbe 8, 422-432 (2010).

353. Ayari, A. et al. Influenza infection rewires energy metabolism and induces browning features in adipose cells and tissues. Commun. Biol. 3, 237 (2020).

354. Wang, J. et al. Porcine reproductive and respiratory syndrome virus activates lipophagy to facilitate viral replication through downregulation of NDRG1 expression. J. Virol. 93, 1-20 (2019).

355. Taylor, M. P. \& Karla, K. Modification of cellular autophagy protein LC3 by poliovirus. J. Virol. 81, 12543-12553 (2007).

356. Dreux, M., Gastaminza, P., Wieland, S. F. \& Chisari, F. V. The autophagy machinery is required to initiate hepatitis $\mathrm{C}$ virus replication. Proc. Natl Acad. Sci. USA 106, 14046-14051 (2009).

357. Wong, J. et al. Autophagosome supports coxsackievirus B3 replication in host cells. J. Virol. 82, 9143-9153 (2008).

358. Nourbakhsh, M. et al. Arylacetamide deacetylase: a novel host factor with important roles in the lipolysis of cellular triacylglycerol stores, VLDL assembly and HCV production. J. Hepatol. 59, 336-343 (2013).

359. Vieyres, G. et al. ABHD5/CGI-58, the Chanarin-Dorfman syndrome protein, mobilises lipid stores for hepatitis C virus production. PLoS Pathog. 12, e1005568 (2016)

360. Brown, J. M. et al. CGI-58 facilitates the mobilization of cytoplasmic triglyceride for lipoprotein secretion in hepatoma cells. J. Lipid Res. $\mathbf{4 8}$, 2295-2305 (2007).

361. Shoemaker, J. P., Hoffman, R. V. \& Huffman, D. G. Trypanosoma cruzi: preference for brown adipose tissue in mice by the Tulahuen strain. Exp. Parasitol. 27, 403-407 (1970).

362. Trindade, S. et al. Trypanosoma brucei parasites occupy and functionally adapt to the adipose tissue in mice. Cell Host Microbe 19, 837-848 (2016)

363. Bechah, Y. et al. Persistence of Coxiella burnetii, the agent of q fever, in murine adipose tissue. PLoS ONE 9, e97503 (2014).

364. Bechah, Y., Paddock, C. D., Capo, C., Mege, J.-L. \& Raoult, D. Adipose tissue serves as a reservoir for recrudescent Rickettsia prowazekii infection in a mouse model. PLoS ONE 5, e8547 (2010). 
365. Neyrolles, O. et al. Is adipose tissue a place for Mycobacterium tuberculosis persistence? PLoS ONE 1, e43 (2006).

366. Combs, T. P. et al. The adipocyte as an important target cell for Trypanosoma cruzi infection. J. Biol. Chem. 280, 24085-24094 (2005).

367. Kennedy, P. G. Clinical features, diagnosis, and treatment of human African trypanosomiasis (sleeping sickness). Lancet Neurol. 12, 186-194 (2013).

368. Ranjithkumar, M. et al. Hyperlipidaemia in trypanosomiasis of naturally infected horses: possible cachexia-anorexia syndrome? Trop. Anim. Health Prod. 45, 417-421 (2013)

369. Wang, A. et al. Opposing effects of fasting metabolism on tissue tolerance in bacterial and viral inflammation. Cell 166, 1512-1525 (2016).

\section{Acknowledgements}

R. Z. and M. S. are supported by grants from the FWF SFB Lipid Hydrolysis (grant number F7302) and SFB Immunometabolism (grant number F83), respectively. R. Z. is additionally supported by the Louis Jeantet Prize 2015 awarded by the Louis Jeantet Foundation.

\section{Author contributions}

Conceptualization was done by M. S. and R. Z.; G. F. G., H. X., M. S. and R. Z. wrote the manuscript; figures were prepared by G. F. G. and M. S.

\section{Competing interests}

The authors declare no competing interests.

\section{Additional information}

Correspondence should be addressed to Martina Schweiger or Rudolf Zechner.

Peer review information Nature Metabolism thanks Dominique Langin and the other, anonymous reviewers for their contribution to the peer review of this work. Primary handling editor: Christoph Schmitt.

Reprints and permissions information is available at www.nature.com/reprints.

Publisher's note Springer Nature remains neutral with regard to jurisdictional claims in published maps and institutional affiliations.

(c) Springer Nature Limited 2021 